\title{
Los hijos del enemigo: las víctimas silenciosas de los crímenes sexuales*
}

\author{
The children of the enemy: the silent victims \\ of armed conflicto
}

\author{
Soledad Torrecuadrada García-Lozano \\ Profesora Titular (Catedrática acreditada) de Derecho Internacional y Relaciones Internacionales. \\ Universidad Autónoma de Madrid \\ s.torrecuadrada@uam.es
}

RECIBIDO EL 29 DE ABRIL DE 2017/ ACEPTADO EL 29 DE JUNIO DE 2017

Resumen: Si los niños, debido a su vulnerabilidad, son víctimas de los conflictos armados en mayor medida que los adultos y los problemas originados por la guerra pueden lastrar su futuro, hay unos niños de los que no se habla, que sufren los efectos de la contienda una vez que esta ha concluido: son los hijos del enemigo, los nacidos como consecuencia de los crímenes sexuales, que debido a su origen son rechazados sistemáticamente por las comunidades maternas. Al estudio de la vulneración de sus derechos dedicaremos las páginas que componen este trabajo.

Palabras clave: conflictos armados, vulnerabilidad, crí menes sexuales, niños.
Abstract: The children, for their vulnerability, are victims of armed conflict to a greater extent than adults and problems caused by war can make their future difficult, there are children who are not spoken, who suffer the effects of conflict once this has been concluded: the enemy's children those born as a result of sexual crimes, which by their origin are systematically rejected by the mother communities. The pages that compose this work study the violation of their rights.

Keywords: armed conflicts, vulnerability, sexual crimes, children.

Sumario: I. INTRODUCCIÓN; II. ¿LOS NIÑOS NACIDOS DE CRÍMENES SEXUALES SON VÍCTIMAS DE GENOCIDIO, LESA HUMANIDAD O CRÍMENES DE GUERRA?; III. VULNERACION DE LOS DERECHOS DE LOS NIÑOS NACIDOS DE LA VIOLACIÓN O DEL EMBARAZO FORZOSO; 1. Pertenencia al grupo y discriminación; 2. Protección de la familia; 3. Derecho a la identidad y a la nacionalidad; 4. ¿Existe un derecho a saber quiénes son los padres biológicos? IV. CONCLUSIONES

* Realizado dentro del Proyecto La evolución de las instituciones jurídicas de protección de menores (financiado por el MINECO/FEDER, convocatoria 2015, referencia: DER2015-69261-R. Investigadora principal: Susana Quicios Molina). 


\section{INTRODUCCIÓN}

$\mathrm{R}$ eflexionar sobre los niños como víctimas de los conflictos armados puede resultar una cuestión reiterativa, pues es sabido que son sus principales víctimas (directas y/o indirectas). Serán víctimas directas en tanto que objeto de algún tipo de violencia, resulten heridos o fallecidos en su transcurso; e indirectas en todas aquellas situaciones que, siendo distintas de las anteriores, afecten a su normal desarrollo físico o psicológico. Así, si las rutinas les proporcionan seguridad y con ello se favorece un correcto desarrollo de su personalidad, la quiebra de aquellas podrá conducir a un efecto distinto del que deseamos para las futuras generaciones, así como a la pérdida de miembros de su núcleo familiar, la suspensión de su formación debido a los ataques, la destrucción que rodea su existencia y otros posibles hechos que, desde una perspectiva psicológica, puedan repercutir negativamente en su formación, desarrollo y crecimiento.

Al finalizar la Segunda Guerra Mundial la UNESCO elaboró dos informes muy interesantes en este punto, uno relativo a los problemas de los niños víctimas de la guerra; y, otro, sobre la situación de los niños polacos bajo la ocupación alemana ${ }^{1}$. En este último se señalan seis derechos de los que son titulares los niños que se ven vulnerados como consecuencia de los conflictos armados: el derecho a la educación, a un desarrollo físico normal, a toda actividad social organizada, a una familia y a una existencia estable, a una nacionalidad propia y a la vida. A ellos hay que añadir, como lo hace informe indicado en primer lugar, los efectos psicológicos originados por las experiencias que han protagonizado o contemplado en el transcurso de estas contiendas.

Sin embargo, no es mi intención en estas páginas referirme a los padecimientos de los niños durante los conflictos armados, cuestiones que han sido ya muy estudiadas por académicos de distintas disciplinas, especialmente médicos y psicólogos, sino a los niños nacidos como consecuencia de aquéllos.

1 El indicado en primer lugar es el Informe preliminar realizado por el Doctor Simone Marcus publicado el 5 de noviembre de 1947. Documento Educ./55; el segundo es Fruto de la reunión de directores de pueblos de niños, producida entre los días 4 y 11 de julio de 1948. El documento en cuestión se publicó el 28 de julio de 1948, es UNESCO/ED/Conf.1/18. Poco después, la misma organización publicaba L'enfance victime de la guerre. Un étude de la situation européenne, par le Docteur Thérèse Brosse, UNESCO, Paris, 1950, que puede leerse en http://unesdoc. unesco.org/images/0013/001337/133701fo.pdf, se trata de un estudio constructivo sobre la situación de los niños que han sufrido la guerra y los posibles remedios para mitigar las consecuencias de la atroz experiencia. 
Se trata de los hijos del enemigo, entendiendo por tales, quienes son fruto de crímenes sexuales ${ }^{2}$, ya sea violación maternidad forzada o los denominados matrimonios forzosos ${ }^{3}$. Es cierto que la categoría de «hijos del enemigo» alcanza también a los que son fruto de relaciones consentidas, pero en este trabajo solo me voy a referir a los primeros, aunque en algunos casos tengamos que hacer alusión a todos ellos en la medida en que comparten con aquellos la discriminación derivada de su origen paterno.

Resulta paradójico que la existencia de múltiple literatura académica acerca de los crímenes sexuales en los conflictos armados ${ }^{4}$, no haya ido acompañada de trabajos en los que se hiciera referencia ni siquiera mínimamente la situación de sus hijos. Podemos justificar el motivo de este silencio en la ubicación del foco de atención en las mujeres, las verdaderas víctimas del crimen cometido identificando, en el mejor de los casos, a los hijos como una consecuencia indirecta de la violación. Esta metodología ha producido el alejamiento de los niños del centro de interés, conduciendo a una omisión intencionada de los nacidos como consecuencia de aquellas atrocidades.

Según R.Ch. Carpenter el motivo de este silencio se encuentra en que el embarazo y la maternidad forzosa se conciben como crímenes tanto contra la mujer como contra los grupos humanos a los que pertenece, omitiendo por ello a los niños que encuentran su origen en el acto criminal's. Según la misma autora $\ll$ Children born of genocidal rape face specific kinds of human rights

2 Vid. junto con la obra referida infra en nota $\mathrm{n}^{\circ}$ 4, los trabajos de Bou Franch, V., «Los crímenes sexuales en la jurisprudencia internacional», Revista Electrónica de Estudios Internacionales (REEI), 2012; «El crimen internacional de esclavitud sexual y la práctica de los 'matrimonios forzados'», Anuario Español de Derecho Internacional, $\mathrm{n}^{\circ} 31,2015$, pp. 65 y ss.; o, Torrecuadrada GarciaLozano, S., «Los crímenes sexuales en los conflictos armados», en Orihuela Calatayud, E. (coord.), Crímenes internacionales y justicia penal. Principales desafios, Thomson-Reuters, 2016, pp. 75 y ss.

3 La definición de «Children born of war», según Mochmann, I.C. y LARSEN, S.U., «'Children born of war': the life course of children fathered by German soldiers in Norway and Denmark during WWII - some empirical results», Historical Social Research, 33, 2008, 1, pp. 347 y ss., alcanza a todos aquellos que sean hijos de un militar enemigo, fuerza de ocupación, de un niño soldado o incluso más recientemente se han incorporado a esta relación los hijos de miembros de operaciones de mantenimiento de la paz, vid. en pp. 350-351.

$4 V i d$. por todos Lirola Delgado, I y Martín MartíneZ, M., Crimenes internacionales de violencia sexual y conflictos armados, Aranzadi, Madrid, 2016. Sabida es la múltiple utilidad de la violación en los conflictos armados: aterrorizan a la población y sirven como un instrumento para la limpieza étnica, entre otras.

5 Carpenter, R.Ch., «Forced Maternity, Children's Rights and the Genocide Convention: A Theoretical Analysis», Journal of Genocide Research, 2000, 2(2), pp. 213 y ss. 
violations that differ both in nature, source, and intent from other aspects of genocidal atrocity ${ }^{6}$.

Debido a lo anterior, la percepción de estos niños «invisibles» es marginal en el ordenamiento internacional, sin que encontremos la más mínima mención a ellos en el Protocolo facultativo a la Convención sobre los derechos del niño acerca de la participación de los niños en los conflictos armados, centrado en la trágica realidad de los niños soldado. Así, los «hijos del enemigo» quedan al margen de las medidas de protección adoptadas respecto de los niños especialmente vulnerables en los conflictos armados, a pesar de que comparten con el resto de los menores su vulnerabilidad mientras dura la contienda y, a diferencia de ellos, las duras condiciones de su existencia se mantienen una vez concluido el conflicto debido a la discriminación de la que son objeto por parte de las comunidades de origen de sus madres, tolerada por el Estado en la inmensa mayoría de las ocasiones. También podemos justificar la omisión en este punto debido a que los niños nacidos como consecuencia de los crímenes sexuales no participan en los conflictos armados, sino que son concebidos en ellos, por lo que son una de sus consecuencias. De todos modos, deberíamos evitar justificar su omisión, desde el convencimiento de que hemos de tener en cuenta su existencia con el propósito de normalizar su subsistencia y evitar la discriminación de la que son silenciosamente víctimas, una vez que ha concluido el conflicto.

El único texto internacional que incorpora en las categorías especiales de niños en los conflictos armados a los que son fruto de una maternidad forzosa es la Declaración y recomendaciones sobre los derechos de los niños en los conflictos armados, conocida como Declaración de Amsterdam ${ }^{7}$. Aunque se limita a mencionarlos sin establecer medidas novedosas en relación con ellos, tan solo recomienda la realización de esfuerzos para evitar su estigmatización ${ }^{8}$, lo que considero es un avance muy importante en un contexto en el que su ausencia es la regla, la mera mención resulta un hallazgo, un reconocimiento de su existencia y de la discriminación de la que son objeto. En consecuencia, con esta única salvedad, el mismo sistema internacional ha contribuido a ocultar y

6 Ibidem. La transcripción del texto se encuentra en la página 214.

7 Se refiere a los niños «who is pregnant as the result of rape or other sexual abuse should have the same rights as an adult woman». El texto completo de la Declaración y las recomendaciones aludidas se encuentra en The International Fournal of Children's Rights, 1994, 413 y ss.

$8 \quad$ Ibid., El mismo texto indica: «Every effort shall be made to prevent the danger of stigmatisation of children born as the result of rape». 
silenciar la marginación que sufren los «hijos del enemigo» debido a que han sido ignorados voluntariamente como personas, así como la vulnerabilidad que les caracteriza.

En este sentido me parece imprescindible profundizar en la situación de estas víctimas, que en algunos casos se han denominado indirectas de la violación de sus madres, pues es precisamente su origen lo que motiva la discriminación y el rechazo tanto en el seno familiar como en el escolar o el más amplio de la comunidad en la que habitan, por citar solo algunos de los más inmediatos 9 . D. Setto considera a estos niños como «a symbol of collective victimhood and a spectacle to discipline a nation damaged by conflict» ${ }^{10}$.

Podemos cuestionar si los niños son víctimas o no del genocidio del que han sido objeto sus madres como consecuencia de la maternidad forzosa, pero lo que es evidente es que la estigmatización que padecen, una vez concluida la contienda, vulnera los derechos de los que todos los menores son titulares y de cuya garantía responsabiliza la Convención sobre los derechos del niño a los Estados partes en este Tratado Internacional ${ }^{11}$. Es, por tanto, desde esta perspectiva de análisis desde la que estudiaremos la situación en la que se encuentran esta categoría específica de «hijos del enemigo».

9 Patricia A. Weitsman, afirma «if these children are born as a consequence of government-orchestrated rape campaigns, thus representing the legacy of violence a country has experience». Weitsman, P.A., «The Politics of Identity and Sexual Volence: A Review of Bosnia and Rwanda», Human Rights Quarterly, n 30, 2008, p. 561 y ss. La transcripción se encuentra en la página 561.

10 Setto, D., «Children Born of Wartime Sexual Violence and the Limits of Existence», Peacebuilding, vol. 3, 2015-2, la versión electrónica de este estudio puede descargarse en la siguiente dirección: http://tandfonline.com/doi/full/10.1080/21647259.2015.1052631?src=recsys\&

11 El artículo tercero de este texto convencional establece el compromiso de los Estados de «asegurar al niño la protección y el cuidado que sean necesarios para su bienestar, teniendo en cuenta los derechos y deberes de sus padres, tutores u otras personas responsables de él ante la ley y, con ese fin, tomarán todas las medidas legislativas y administrativas adecuadas». Recordemos en este punto que la Convención sobre los derechos del niño tiene por objeto adoptar medidas de protección necesarias para los menores de edad, prestando especial atención a los que se encuentran en grupos vulnerables (de hecho, el Comité de Naciones Unidas sobre los derechos del niño, dedica los parágrafos 75 y 76 de su observación general n ${ }^{\circ} 14$ sobre el interés superior del menor a los niños en situación de vulnerabilidad o pertenecientes a grupos vulnerables) y reconozcamos que los hijos de una mujer violada han de sobrevivir en una situación de vulnerabilidad que amerita que se consideren sus derechos de forma concreta. Es cierto que la Convención entró en vigor en 1990, pero también lo es que no nos encontramos ante un texto constitutivo de nuevos derechos para sus titulares, sino de un recordatorio y concreción de los derechos de los que somos titulares todas las personas al grupo humano formado por los menores de edad. 
La historia es tozuda y reiterativa en muchas cuestiones y clarísimamente en ésta, ya que en los conflictos recientes, como el yugoslavo se detectaron abortos, abandonos ${ }^{12}$ e infanticidios ${ }^{13}$, rechazo social y estatal, comportamientos que aunque nos alarmen distan mucho de ser novedosos. Así, entre las contiendas producidas en la Primera Guerra Mundial, en los primeros decenios del siglo XX, se han documentado estas reacciones, entre las que resulta más llamativa, la tolerancia al infanticidio por parte de los tribunales belgas, en los supuestos de mujeres violadas por las tropas alemanas ${ }^{14}$. Por tanto, la evolución humana no afecta a los comportamientos durante los conflictos armados, salvo en que a deshumanización se refiere, dado que siempre somos capaces de aumentar la crueldad, aunque la reacción de las víctimas sea similar a la de aquellas mujeres que podrían, por edad, ser sus bisabuelas.

12 Hammer, J., «Born under a bad sign», en http://europe.newsweek.com/born-under-bad-sign177862 ? rm=eu muestra la realidad de los niños concebidos como consecuencia de violaciones durante la guerra de Yugoslavia y Ruanda, conflicto este último en el que, según el autor, «tens of thousands of Tutsi women like Mukamagera were raped by Hutu fighters and neighbors». En Ruanda, el aborto es contrario a la Ley por lo que el recurso a él es un delito y un pecado para la mitad de la población, que según las estadísticas, es católica. Decenas de miles de mujeres fueron también atendidas como consecuencia de violaciones o mutilaciones en los hospitales de North Kivu, en el Congo, por lo que el número de víctimas de estos crímenes y de potenciales nacimientos como consecuencia de aquellos, se incrementa considerablemente cada vez que nos aproximamos a un conflicto armado. Ver en MAEDL, A., «Rape as Weapon of War in the Eastern DRC? The Victim's Perspective», Human Rights Quarterly, nº 33, 2011, pp. 120 y ss. La referencia en cuestión se encuentra en la página 133. HorWOOD, C. (ed.), The Shame of War: Sexual Violence adainst Women and Girls in conflicto, OCHA/IRIN, Malta, 2007, aporta datos escalofriantes sobre crímenes sexuales en conflictos armados en distintas partes del mundo (pp. 12 y ss.) Por su parte, Eriksson BaAz, M. y STERn, M., «Why Do Soldiers Rape? Masculinity, Violence and Sexuality in the Armed Forces in the Congo (DRC)», International Studies Quarterly, vol. 53, $\mathrm{n}^{\circ} 2,2009$, pp. 495 y ss. Concretan un poco más la cifra, indicando que fueron más de 36.000 víctimas de violaciones.

13 Vid. Salzman, T., «Rape camps as a means of ethnic cleansing: Religious, cultural and ethnic responses to rape victims in the former Yugoslavia», Human Rights Quarterly, 20, 1998, pp. 348 y ss. También, respecto de la situación en Perú, en Theidon, K., «Ocultos a plena luz: los niños nacidos de la violencia sexual en tiempos de Guerra», Análisis Político, nº 85 , septiembre-diciembre 2015, pp. 158 y ss. Al infanticidio y al aborto con hierbas se refiere en la página 164. También CARPENTER, R.Ch., «Forced Maternity...», op. cit., supra nota $\mathrm{n}^{\circ} 5$ (especialmente p. 228); Li QIN, L., «Situating Children of Genocidal Rape: Towards Membership in an Ethnic Community», Singapore Law Review, 2003, 23, pp. 45 y ss., especialmente p. 57, se refiere a la tolerancia generalizada de las violaciones de derechos humanos contra los niños.

14 Vid. Audoin-Rouzeau, S., L'enfant de l'ennemi. viol, avortement, infanticide pendant la Grande Guerre, Champs Histoire, Paris, 1995 ( $3^{\text {a }}$ ed. 2013), pp. 15-41, se refiere al proceso contra Josephine Barthélemy por infanticidio de un niño concebido por una violación de un soldado alemán, en el que se muestra la tolerancia a este crimen ante la posibilidad de tener un hijo del enemigo. 
La estigmatización social de madres e hijos es una amenaza para todos los supuestos de hijos del enemigo (no solo para los que son fruto de crímenes sexuales), que algunos Estados han intentado mitigar sin éxito. Así por ejemplo, el gobierno de Bangladesh se esforzó en que las mujeres violadas por los paquistaníes fueran consideradas como heroínas nacionales, aunque finalmente tanto ellas como los hijos resultaron rechazados por las familias y la mayoría de estos últimos víctima de infanticidio, abandonados o dejados en instituciones ${ }^{15}$. De ahí que en la medida de lo posible, las mujeres violadas se escuden en un silencio que consideran protector con el que pretenden normalizar las condiciones de su existencia, entendiendo que de lo que no se habla no existe y, en cuanto tal, no hay motivo para su marginación social, aunque con este comportamiento contribuyan a la impunidad de quienes han cometido estos crímenes sexuales. Esto ocurre en todos los lugares, incluso en Timor, donde las víctimas de las violaciones respondieron con la negación y el silencio, como herramientas para procurar seguir con su vida «lack of recognition by existing transitional justice mechanisms of gender-based violence, and the Catolic Church's ambivalent and somewhat problematic response to the children and their mothers» ${ }^{16}$.

A pesar de lo atroz de la situación recién apuntada, no solo los niños nacidos de la violación sufren discriminación y vulneraciones en sus derechos. La historia nos muestra los hijos del enemigo resultan estigmatizados en múltiples aspectos, unos y otros han sido objeto de denominaciones peyorativas en distintos lugares del mundo, épocas y características de los conflictos: los enfants de boche en Francia, devil's children, en Rwanda, son/daughter of Kony, children of hate, genocidal children, unwanted children, children of bad memories o children of shame en Kosovo, Children of the enemy en el este de Timor, Dust of life o American infected babies en Vietnam, soldadito en Guatemala, Paraquitos en Colombia, los regalos de los soldados, hijo de nadie o fulano en Perú ${ }^{17}$.

15 CARPEnTER, R.Ch., «Forced Maternity...», op. cit., 2000, 2(2), p. 213 y ss. La idea del texto se encuentra en la p. 223, también; L. LI QIN, «Situating Children of Genocidal Rape: Towards Membership in an Ethnic Community», Singapore Law Review, 2003, 23, pp. 45 y ss., especialmente p. 57.

16 Vid. en Harris Rimmer, S., «'Orphans' or Veterans?: Justice for Children Born of War in East Timor», Texas International Law fournal, vol. 42, 2007, pp. 323 y ss, la transcripción del texto se encuentra en la página 331.

17 Existen multiples listados que contienen la denominación despectiva con la que se conoce a estos niños, esta está tomada de THEIDON, K., «Hidden in Plain Sight. Children Born of Wartime Sexual Violence», Current Anthropology, vol. 56, suplemento 12, diciembre 2015. 
Desafortunadamente, los niños en cuya situación profundizaremos en las páginas que siguen han existido en la inmensa mayoría de los conflictos armados, sean internacionales o no, continúan a día de hoy siendo los grandes olvidados pues no existen informes de relatores especiales de Naciones Unidas específicamente referidos a ellos $^{18}$, ni medidas internacionalmente adoptadas o auspiciadas para su protección ${ }^{19}$. Vamos a ubicar como protagonista de nuestra reflexión a los hijos, no tanto desde la perspectiva del derecho humanitario como del de los derechos del niño, dado que la estigmatización de la que son víctimas se produce especialmente en situaciones post-conflicto. Mi propósito es primero descartar su consideración de víctimas de los crímenes en los que encuentran su origen, para identificar las vulneraciones de los derechos humanos de las que son objeto estos niños así como las medidas a adoptar para que una vez producido el delito principal (la violación y embarazo forzoso ${ }^{20}$ ), los niños afectados puedan superar los problemas que potencialmente derivan para su desarrollo para que la situación que origina su situación no quiebre definitivamente su futuro.

\section{II. ¿LOS NIÑOS NACIDOS DE CRIMENES SEXUALES SON VÍCTIMAS DE GENOCIDIO, LESA HUMANIDAD O CRIMENES DE GUERRA?}

La cuestión que se formula en la rúbrica que precede a estas palabras se encuentra motivada por la potencial calificación de los crímenes sexuales dentro de uno de los tres tipos (lesa humanidad, genocidio o crimen de guerra) a los que puede reconducirse el comportamiento en el que encuentran su origen: la violación. Es evidente que los abusos sexuales y la violación vulneran los derechos inherentes a la dignidad humana, el derecho humanitario y el derecho penal internacional, dado que puede constituir un crimen de lesa

18 Aunque es cierto que el Informe redactado por Graça Machel (Repercusiones de los conflictos armados sobre los niños, de 26 de agosto de 1996, Doc. A/51/306) se refiere a los niños en general, en algunas ocasiones como en la Parte Tercera, dedicada a la pertinencia y adecuación de las normas vigentes en materia de protección de los niños, página 66, parágrafos 204 y ss., por lo que sus indicaciones alcanzan -evidentemente- a los niños que nos ocupan.

19 No existen normas con carácter particular dirigidas a ellos, lo que no implica que no les resulten de aplicación las existentes sobre por ejemplo, menores no acompañados u otras que puedan, según los casos, proteger también a estos menores en situaciones de vulnerabilidad.

20 Vid. Boon, K., «Rape and Forced Pregnancy under the ICC Statute: Human Dignity, Autonomy and Consent», Columbia Human Rights Law Review, n 32, 2001, pp. 625 y ss. 
humanidad ${ }^{21}$, un crimen de guerra (de acuerdo con el Estatuto de Roma) si en lugar de ser un hecho aislado resulta «parte de un ataque generalizado o sistemático contra una población civil» $\mathrm{o}$ «como parte de un plan o política o como parte de la comisión en gran escala de tales crímenes $\gg^{22}$ o de genocidio ${ }^{23}$. En este último caso, las violaciones sistemáticas vayan o no seguidas de embarazos forzados, siempre que se realicen con la intención «de destruir total o parcialmente a un grupo nacional, étnico, racial o religioso como tal», serían constitutivas de genocidio, al provocar daños graves «a la integridad física o mental de los miembros del grupo», pero además, tomando el ejemplo ruandés, «the deliberate impregnation of Tutsi women by Hutus sought to undermine the social fabric of communities» ${ }^{24}$. En consecuencia, si la violación que tiene como resultado el nacimiento de un niño puede ser considerada como crimen de guerra, lesa humanidad o genocidio, convendríamos que estos menores encuentran su origen en una norma imperativa de Derecho Internacional: la que proscribe estos comportamientos.

Las violaciones de la población civil femenina no son una novedad, conocidas son las de las tropas alemanas en Ucrania y en el frente soviético, la de las tropas aliadas en Berlín ${ }^{25}$, solo por referirnos a algunas de las producidas

21 No es una novedad, pues ya se contenía como tal en la Control Council Law n ${ }^{\circ} 10$, Punishment of persons guilty of war crimes, crimes against peace and against humanity, cuyo artículo 2.c reproducía la definición de lesa humanidad de los estatutos de los tribunales de Nuremberg y Tokio. Vid. en http://avalon.law.yale.edu/imt/imt10.asp. Este Consejo se creó como consecuencia de los acuerdos de paz y sentaba las bases homogéneas para el enjuiciamiento de los criminales de guerra que no serían juzgados en el tribunal de Nuremberg. Por ello, la identidad no puede extrañarnos.

22 Vid. respectivamente los artículos 7.1.g) y artículo 8.2.b) apartado xxii y d) apartado vi. El Derecho español reproduce la calificación de la violencia sexual en conflicto armado como crimen de lesa humanidad en los mismos términos indicados en el texto en el artículo 607 bis del Código penal.

23 Vid., entre otros. Meron, T., «Rape as a Crime under International Humanitarian Law», American fournal of International Law, $\mathrm{n}^{\circ} 87,1993$, pp. 424 y ss.

24 BARROW, A., «UN Security Council Resolutions 1325 and 1820: constructing gender in armed conflict and international humanitarian law», International Review of the Red Cross, vol. 92, n. 877, marzo 2010, pp. 221 y ss. La referencia del texto se encuentra en la página 222.

25 En la guerra de Bangladesh de 1971 se calcula que hubo 25.000 niños nacidos de la violencia sexual. Vid. en Bina D'Costa, «Tragic Silence over Bangladesh's Babies of War 1971», en South Asia Citizens Web: http://www.sacw.net/article 581.html). En los territorios ocupados por la armada roja, se calcula que de las violaciones atribuidas a sus miembros «were born as a result of the estimated 1,5 to 2 million rapes is unknown and only little is know about the mothers, children and their lives. But information accessible so far indicates that these children were often discriminated against and stigmatized as «Russenkinder» in post-war Germany and were often rejected by traumatized mothers and excluded by their family» (Mochmann, I.C. y LaRSEN, S.U., «The Human 
en la Segunda Guerra Mundial. Es cierto que, históricamente se concebían como un mero daño colateral de las contiendas ${ }^{26}$, que resultaban justificadas por el impulso natural de los combatientes. Esta percepción afortunadamente ha cambiado como consecuencia de la visibilidad de los brutales crímenes cometidos, lo que ha permitido la toma de conciencia de la necesidad de adoptar cuantas medidas resulten necesarias para su prevención y represión ${ }^{27}$. Objetivo que, a todas luces, ha fracasado si tenemos en cuenta la reiteración de las violaciones que se multiplican en brutalidad ${ }^{28}$.

La pregunta que hemos de formular a continuación es si los niños nacidos como consecuencia de estos crímenes pueden considerarse, igual que sus madres, víctimas de lesa humanidad, crimen de guerra o genocidio, puesto que su estigmatización deriva precisamente de su concepción. En primer lugar, por la situación en la que sobreviven, pueden considerarse víctimas indirec-

Rights of Children Born of War: case analyses of Past and present conflicts», Historical Social Research, 35, 2010, 3, pp. 268 y ss. La frase transcrita en el texto se encuentra en la página 277). Según los mismos autores, supuestos objetivamente similares ocurrieron en otros lugares «the biological origin was often kept a secret, the topic of the Russian father was a taboo, the children grew up believing the stepfather was the biological father, mother did not want to tell anything, and the children -for lack of information- often search in vain to their biological roots».

26 Vid. informe http://www.un.org/womenwatch/daw/public/w2apr98.htm\#part2

27 Aunque hay autores que cuestionan brutalidad con la que se ha calificado el comportamiento alemán de zonas neutrales u ocupadas en la Primera Guerra Mundial, como HARRIS, R., «The «Child of the Barbarian»: Rape, Race and Nationalism in France during the First World War», Past \& Present, $\mathrm{n}^{\circ} 141$ (nov. 1993), pp. 170 y ss. O Gullace, N.F., «Sexual Violence and Family Honor: Bristish Propaganda and International Law during the First World War», The American Historical Review, vol. $102\left(\mathrm{n}^{\mathrm{o}} 3\right)$ junio 1997, p. 714 y ss. Que afirma que «the gendered representation of German atrocities provided British propagandists with a vivid and evocative set of images that could be used to explain the arcane language of international law to a democratic public increasingly empowered to support or reject its enforcement», este texto figura en la página 716. Encontramos referencias claras a la brutalidad de las violaciones producidas en la Primera Guerra Mundial, como nos relata S. Audoin-Rouzeau (vid. supra en nota nº14), así como el debate mantenido sobre el aborto en estas circunstancias y las soluciones a aportar a las mujeres embarazadas como consecuencia de la violación por parte del enemigo. A pesar de lo interesante de los argumentos esgrimidos durante los debates (147-254), el resultado fue decepcionante. Debates que, desde una perspectiva mucho más crítica, figura también en el estudio de Ruth Harris.

28 Vid. Maedl, A., «Rape as Weapon of War in the Eastern DRC? The Victim Perspective», Human Rights Quarterly, n 33, 2011, p. 128 y ss. En Bangladesh a comienzos de la década de los años setenta, las violaciones y los embarazos forzados fueron un modo de aterrorizar a la población. Vid. en este sentido D'CosTA, B., «Tragic Silence over Bangladesh's Babies of War of 1971», en South Asia Citizens Web, http://www.sacw.net/article581.html, una vez finalizada la contienda, Paquistán negó cualquier responsabilidad en los hechos referidos que nunca ha reconocido. 
tas, ante la imposibilidad de verse alcanzadas por la definición de víctima que contiene la Declaración sobre los principios fundamentales de justicia para las víctimas de delitos y del abuso de poder ${ }^{29}$, que establece la necesidad de haber sufrido «daños, inclusive lesiones físicas o mentales, sufrimiento emocional, pérdida financiera o menoscabo sustancial de sus derechos fundamentales», como consecuencia del delito cometido. En el caso que nos ocupa, si bien es cierto que el origen de su sufrimiento se encuentra en el momento de su concepción, quienes estigmatizan al niño son los miembros de su entorno más próximo. También, en este sentido, cabría entender que debido al crimen del que fue víctima la madre pudo producirle complicaciones derivadas de la situación o del estrés postraumático, afectó a la salud del niño, aunque es difícilmente sostenible en este punto dado que igualmente si la mujer hubiera dispuesto de la atención médica necesaria probablemente esa afectación no se habría producido.

Por lo demás, considerar a los niños nacidos de crímenes sexuales como víctimas de los tipos delictivos de los que fueron objeto sus madres resulta complicado pues si bien está claro que en la maternidad forzosa y en la violación hay un agresor y un agredido, cuando nos referimos a los hijos nacidos como consecuencia de estos comportamientos, podemos identificar a la víctima en los hijos pero ¿quién es el agresor? ¿el padre? ¿el propio niño? La construcción filosófica puede resultar complicada en este punto ${ }^{30}$. Por lo demás, el niño no existe cuando se produce la violación, por lo que resulta una afirmación arriesgada en la medida en que nos estaríamos ubicando en el contexto de los derechos futuros o de titularidad de una persona inexistente aún. Sin embargo, es claro que no son fruto de una elección responsable de los padres (al menos de las madres) y, por otra parte, los padres no responden de sus obligaciones parentales, pues no asumen las obligaciones derivadas de esa paternidad biológica, motivo por el cual podremos considerar que la falta de cumplimiento de estas obligaciones paternas colocan al niño en una situación de vulnerabilidad económica por la que debería responder el padre, pero no por los delitos de lesa humanidad, crimen de guerra o genocidio, sino por el incumplimiento del deber de crianza y protección del que son titulares los progenitores en aplicación del artículo 18 de la Convención sobre los derechos del niño.

29 En el anexo a la Resolución 40/34 de la Asamblea General de las Naciones Unidas, de 29 de noviembre de 1985.

30 Ver sobre esta cuestión GoOdHART, M., «Sins of the Fathers: War Rape, Wrongful Procreation, and Children's Human Rights», Fournal of Human Rights, n 6, 2007, pp. 307 y ss. 
Siguiendo esta lógica de diferenciación entre la mujer como víctima y el niño, en su caso, de forma indirecta, la estrategia amplia de las Naciones Unidas sobre la asistencia y el apoyo a las víctimas de la explotación y los abusos sexuales cometidos por personal de las Naciones Unidas y personal asociado, distingue entre las víctimas de estos comportamientos, que son las mujeres, y los niños nacidos como consecuencia de ello ${ }^{31}$.

Pero, aun superando esta dificultad conceptual, es claro que no pueden considerarse víctimas de crímenes de guerra (art. 8 del Estatuto de Roma) ni de lesa humanidad (art. 7 del mismo texto convencional) porque los niños así nacidos permanecen al margen del alcance de ambas categorías. Lo mismo ocurre con el genocidio, aunque cabría, considerando la definición contenida tanto en la Convención de 1948 para la prevención y sanción del delito de genocidio. Así, los niños nacidos de crímenes sexuales solo podrán ser víctimas de genocidio si sus embarazos son una forma de evitar nacimientos en el seno del grupo humano al que pertenece la madre (art. 2.d de la Convención) ${ }^{32} \mathrm{o}$, cabría quizá, considerarse de este modo si existiera un traslado por la fuerza de niños de un grupo a otro (art. 2.e).

La justificación de la primera categoría se encuentra partiendo de la visión patriarcal de la identidad, conforme a la cual, es el padre quien transmite la identidad, motivo por el que la maternidad forzosa de miembros de otro grupo humano si bien puede no impedir los nacimientos dentro del grupo, sí que interfiere en ellos, puesto que las mujeres alumbran a niños pertenecientes a un grupo diferente al grupo al de éstas, desde esta perspectiva forman parte del grupo paterno, el agresor. La justificación de la segunda categoría partiría de la hipótesis contraria, los niños nacidos como consecuencia de esa maternidad forzada son miembros del grupo, pero la aplicación del artículo 2.e) sería posible en dos situaciones: primera, dado que se considera que los niños heredan la identidad del padre, pertenece a un grupo étnico mixto o mestizo que no es reconocido como miembro de aquel al que pertenece la madre (pensemos en el caso del conflicto yugoslavo), en consecuencia «One can only speculate as to how a generation of such children will fare, living among people who have just concluded a 'brutal war in which the purity, and indeed the

31 Es la resolución 62/214, aprobada por la Asamblea General el 21 de diciembre de 2007. La referencia del texto se encuentra en el apartado «definiciones», página 3, parágrafo $5 \mathrm{~d}$ ) por lo que se refiere a las víctimas y e) a los niños.

32 Charli Carpenter, R., «Surfacing Children: Limitations of Genocidal Rape Discourse», $\mathrm{Hu}$ man Rights Quarterly, 22, 2000, p. 428 y ss., pp. 452 y 463. 
very survival, of nationalities has been held so consciously in the fore.' ${ }^{33} \mathrm{En}$ consecuencia, no habrá un traslado físico, sino una falta de reconocimiento del niño como miembro del grupo humano en el que habita por lo que tampoco resultaría atribuible a quien perpetró el crimen sexual, sino al entorno próximo al menor; la segunda, se encontraría en las adopciones internacionales en masa de los niños nacidos como consecuencia de las violaciones en tiempo de guerra, o en el intento de las autoridades noruegas en la Segunda posguerra Mundial de trasladar a Australia como mano de obra a nueve mil hijos de soldados alemanes oferta que, según K. Olsen, los australianos no aceptaron ${ }^{34}$. Sin embargo, estos traslados de niños de un grupo a otro no serían atribuibles al progenitor, a quien resulta atribuible el crimen sexual, sino al entorno más próximo del menor.

Visto lo anterior, no resulta conceptualmente posible considerar al niño víctima de genocidio, aunque esta conceptualización podría ser beneficiosa para evitar la estigmatización. Ciertamente, pueden considerarse víctimas de sus padres violadores, puesto que su rechazo tiene su origen precisamente en aquellos, aunque si no hubiera sido por ellos el niño no habría nacido. La vulneración de sus derechos tiene ese origen de modo innegable, pero es la comunidad, la familia, la escuela o el Estado quienes en la actualidad discriminan al niño. En consecuencia, el origen de la estigmatización se encuentra en su concepción pero los sujetos activos de esta son distintos de quien violó a su madre.

Como mucho, podríamos compartir la calificación indirecta de la culpabilidad de los violadores respecto de la vulneración de los derechos de los niños. Es cierto que son culpables del crimen que cometieron y cuya víctima es la mujer, por el que han sido juzgados en ocasiones, siendo destinatarios por ello, de las penas que les correspondieran, en su caso. Sin embargo, no son responsables frente a los niños de las vulneraciones en sus derechos que sufren en la actualidad. A pesar de eso, sí que es cierto que si hicieran frente a la manutención de los pequeños podría mejorar su situación dentro del grupo vulnerable pues al menos mejoraría su situación económica, alejándoles del

33 Katherine Wing, A. y Merchán, S., «Rape, Ethnicity, And Culture: Spirit Injury From Bosnia To Black America», Columbia Human Rights Law Review, 25, 1993-1994, p. 1 y ss, la transcripción del texto se encuentra en la página 20.

34 OlSEN, K., «Norwegian war children's work for justice - the role of archives», Comma: International fournal on Archives, vol. 1, $\mathrm{n}^{\circ} 2$, pp. 47-56. En el mismo sentido se pronuncia VALDERHAUG, G., en «Memory, Archives and Justice, a Norwegian perspective», Comma, International fournal on Archives, 2005.3, pp. 1 y ss. Aunque eleva la cifra a 12.000 (p.2). 
contexto de vulnerabilidad económica que les resulta característica, que es uno de los grandes problemas que les afectan.

En todo caso, la estigmatización de estos niños deriva de la identificación por parte de su entorno más próximo con los agresores y no con las víctimas ${ }^{35}$, lo que afecta como mínimo a su derecho a la salud en la medida en que provoca daños físicos y psicológicos. Así, el hijo de una mujer violada, más aún si lo ha sido como resultado de un crimen colectivo, ha de convivir (cuando no ha sido abandonado, abortado o víctima de un infanticidio) con las secuelas psicológicas de su madre y el sentimiento de saberse culpable de ellas, además del rechazo de la comunidad.

Por otra parte, en ocasiones son olvidados en las políticas de construcción y consolidación de la paz cuando no se consideran un obstáculo para ponerlas en práctica, al ser el recuerdo constante de lo ocurrido y el temor a que hereden la barbarie de sus progenitores violadores ${ }^{36}$. La estigmatización social será distinta en función de los rasgos culturales que le caractericen, «As a result of a patriarcal identity, the community frequently ends up being the oppressor ${ }^{37}$. En otros casos, el solo hecho de ser hijo ilegítimo o no matrimonial, como en el caso de la cultura Acholi, al norte de Uganda, implica ya la estigmatización derivada de pertenecer al grupo social más bajo ${ }^{38}$, aspecto al que nos referiremos en el epígrafe siguiente.

\section{VULNERACIÓN DE LOS DERECHOS DE LOS NIÑOS NACIDOS DE LA VIOLACIÓN O DEL EMBARAZO FORZOSO}

Una primera cuestión que llama nuestra atención es el hecho de que carezcamos de datos, aunque sean aproximados, del número de niños que nacieron como consecuencia de las atrocidades que suponen los crímenes sexuales.

35 Normalmente es así, aunque en la realidad actual de Bosnia-Herzegovina se les contempla también como víctimas, según el trabajo de ERJAVEC, K. y VolCIC, Z., «'Tarjet', 'cancer' and 'warrior': Explorig painful metaphors of self-representation used by girls born of war rape», Discourse \&SSociety, 21 (5), 2010, pp. 524 y ss. La idea del texto figura en la página 525.

36 Vid. Blankers, E., «A new generation: How refugee trauma affects parenting and child development», Disertación, puede verse en https://dspace.library.uu.nl/handle/1874/284735 El testimonio de una madre violada en tiempo de guerra que resulta muy ilustrativo de la realidad que queremos transmitir.

37 VAN Ee, E. y KLEBER, R.J., «Growing Up Under a Shadow...», op. cit., supra nota n 22, p. 391.

38 Idem. Nota anterior. 
Las cifras que se manejan son inciertas, en ocasiones por los abortos, abandonos, en otros debido al fallecimiento del niño (por causas naturales o no) o por el silencio de las madres (que consideran protector), con el que pretenden ocultar el origen de sus embarazos pues reconocer el hecho «include the fear of stigmatization, shame, the fear of retributive violence, and the inability to reach authorities» ${ }^{39}$. En todo caso, R. Charli Carpenter calcula que decenas de miles de niños nacieron como consecuencia de violaciones o embarazos forzosos solo los años noventa ${ }^{40}$. En los momentos posteriores a la Segunda Guerra Mundial, se calcula que fruto de las violaciones de las tropas de ocupación soviética nacieron en Alemania entre decenas de miles y dos millones de niños, cuya existencia ha comenzado a visualizarse una vez que transcurrieron cuarenta años de la finalización de la contienda ${ }^{41}$.

La ausencia de denuncia de la violación cuando viene acompañada de embarazo resulta especialmente característica de los entornos en los que el aborto es ilícito. Si además nos encontramos en sociedades patriarcales en las que la virginidad está íntimamente ligada a las ideas de continuidad cultural, resultando un valor importante, entenderemos su silencio. En esas sociedades patriarcales, la participación social de las mujeres depende del matrimonio, por lo que se encuentra vedada a las mujeres solteras. P.A. Weitsman lo expresa con las siguientes palabras: «if a woman is unmarried, her worth derives from her status as a virgin. Once raped, society no longer deems her marriageable or socially viable ${ }^{42}$. Si unimos esta característica a la anterior, comprenderemos que la lógica imperante en estos grupos humanos implica la marginación y estigmatización de las mujeres violadas, pues si estaban sol-

39 CoHEN, D. K., «Sexual violence in armed conflict: Introducing the SVAC dataset, 1989-2009», Fournal of Peace Research, 2014, vol. 51 (3), pp. 418 y ss. Las frases transcritas en el texto se encuentra en la página 421.

40 Carpenter, R.Ch. (ed.), Born of War: Protecting Children of Sexual Violence Survivors in Conflict Zones, Kumarian Press, 2007, p. 2.

41 Van Ee, E. y Kleber, R.J., «Growing Up Under a Shadow: Key Issues in Research on and Treatment of Children Born of Rape», Child Abuse Review, vol. 22, pp. 286 y ss. La referencia indicada en el texto se encuentra en la página 387. GebHaRdT, M., Crimes Unspoken: the rape of German Women at the End of the Second World War, Polity Press, Cambridge, 2016, reduce la horquilla a cientos de miles de niños nacidos como consecuencia de las 860.000 violaciones de mujeres alemanas y austriacas cometidas por las tropas de ocupación. Se trata siempre de cifras aproximadas por los motivos vistos en el texto.

42 Vid. Weitsman, P.A., «The Politics of Identity and Sexual Violence: A Review of Bornia and Rwanda», Human Rights Quarterly, n 30, 2008, pp. 561 y ss. La frase transcrita en el texto se encuentra en la p.564. 
teras en el momento en el que se produjo este delito, van a ver impedida la posibilidad de casarse y, con ello su participación social, mientras si estaban casadas, se arriesgan a verse repudiadas por sus maridos. El resultado en ambos casos será el mismo: su marginación y estigmatización social, de modo que la mujer y el hijo emprenden un camino hacia la pobreza, pues carecen de ayudas económicas, sin posibilidad de vuelta atrás. No es baladí en este punto subrayar que «the rape victim was in turn ostracized by her family and community $\gg^{43}$.

En el caso de las víctimas timorenses, por ejemplo, la dificultad de aceptar al niño fruto de un embarazo forzoso «rather than define them as of the enemy, may be explained by the low status of Timorese women and the fact that women's social status often derives from motherhood» ${ }^{44}$. En todo caso, con independencia de las expectativas sociales de cada mujer, la aceptación de un hijo fruto de una violación en el contexto que nos ocupe es psicológicamente muy complicada para la víctima.

En este tipo de sociedades, hay mujeres embarazadas que acudirán a interrupciones de embarazo poco o nada seguras (pues recordemos que, en las sociedades patriarcales suele tratarse de un comportamiento ilícito) o, en su defecto, si esto resulta muy caro, directamente al infanticidio. En todo caso, parece previsible que la herencia de los rasgos étnicos característicos del grupo humano al que pertenece el padre incremente las posibilidades recurrir a esta traumática solución ${ }^{45}$ cuando no al abandono o estigmatización.

Aunque tendamos a visualizar este tipo de comportamientos como alejados de esta atalaya privilegiada que es el primer mundo, no podemos olvidar que se han producido en los conflictos armados anteriores pero también y para nuestra vergüenza, en los más próximos tanto temporal como

43 Burds, J., «Sexual Violence in Europe in World War II, 1939-1945», Politics «Society, vol. 37, $\mathrm{n}^{\circ} 1$, marzo 2009 , pp. 35 y ss. La referencia del texto se encuentra en la página 61.

44 Vid. en Harris Rimmer, S., «'Orphans' or Veterans?: Justice for Children Born of War in East Timor», Texas International Law fournal, vol. 42, 2007, pp. 323 y ss, la transcripción del texto se encuentra en la página 329.

45 No podemos olvidar que el infanticidio vulnera claramente el derecho a la vida proclamado en la Declaración Universal o los Pactos de Nueva York y concretado en la Convención de Naciones Unidas sobre los Derechos del niño de 1989 (art. 6). Se ha documentado infanticidio en los conflictos de Bangladesh, la antigua Yugoslavia, Ruanda y Darfur, según MitcheLL, K.T., «Children Bron from Rape: verlooked Victims of Human Violations in Conflict Seetings», ver en http://www.jhsph.edu/academics/degree-programs/master-of-public-health/_pdf/Mitchell_ Capstone_Paper_2005.pdf 
espacialmente. Refirámonos como ejemplo de los recientes, a los producidos como consecuencia de la guerra de los Balcanes ${ }^{46}$, en Bangladesh, Darfur o del intento de los hutus para acabar con los tutsis en el conflicto de Ruanda, en la década de los años noventa ${ }^{47}$. A pesar de los antecedentes históricos, hemos tenido que esperar hasta el año 2000 para que el Consejo de Seguridad se hiciera eco de la violencia sexual, no así a los hijos fruto de la misma, se trata de un primer paso, pero de breve recorrido, lo que resulta muy criticable, teniendo en cuenta la magnitud del horror tanto en las madres como en los hijos ${ }^{48}$.

Como se ha reiterado en páginas anteriores, son los orígenes del niño, de su concepción, los que parecen excluirle o al menos silenciarle en el ámbito tanto del Derecho Internacional como del Derecho Humanitario, parece que su situación no es una prioridad, máxime si con ello podemos dificultar la reconciliación entre las partes en conflicto. Por tanto, una razón más para que tampoco encontremos demasiadas referencias a ellos en los documentos que se refieren a la reconstrucción post-conflicto. En todo caso, el punto de partida que hemos de adoptar, como afirma L.L. Qin, debe ser el cumplimiento eficaz de la obligación del Estado «of undertake and encourage such extralegal efforts may be founded upon its obligations to combat discrimination

46 Una perspectiva de análisis interesante sobre el conflicto en Bosnia es el firmado por WING, A.K. y Merchán, S., «Rape, Ethnicity...», op. cit., supra nota ${ }^{\circ} 33$. En este trabajo se explica desde la perspectiva de la identidad cultural lo que supusieron los crímenes sexuales cometidos durante el conflicto para los musulmanes bosnios. Hay una frase en la página 24 que sirve de síntesis de algunas reflexiones formuladas: «The systematic rape of Muslim women in Bosnia could potentially result in the complete destriction of the Muslim social fabric».

47 También hubo mujeres hutus violadas por las fuerzas tutsis, pero en la medida en que el número fue inferior carecen del reconocimiento que les corresponde a las tutsis, aunque fueran víctimas del mismo crimen, aquellas que tuvieron hijos como consecuencia de la violación sufrida permanecen junto con ellos en un grupo de mayor vulnerabilidad que las mujeres tutsis y los suyos.

48 Se trata de las resoluciones del Consejo de Seguridad 1325, de 31 de octubre de 2000 y 1820 , de 19 de junio de 2008. Bien es cierto que se había reconocido puntualmente la década anterior en relación a las situaciones en Yugoslavia y Ruanda, en los respectivos estatutos de los Tribunales Penales Internacionales creados con este objeto. Tanto en las resoluciones 827, de 25 de mayo de 1993 como en la 955, de 8 de noviembre de 1994, se consideran las violaciones como crímenes de guerra y, en consecuencia, objeto de la competencia de ambos tribunales. También en 2007, condenó la violencia sexual en la República Democrática del Congo en su Resolución 1497 (2007), de 21 de diciembre de 2007. Es cierto que la Convención de Ginebra sobre la protección de la población civil en tiempos de guerra establecía el deber de proteger a las mujeres contra «todo atentado a su honor y, en particular, contra la violación, la prostitución forzada y todo atentado a su pudor» (art. 27), por lo que la incorporación en los citados Estatutos era imprescindible. 
and to undertake all appropriate measures for the implementation of rights recognized by Children Rights Convention ${ }^{49}$.

Nos encontramos ante un grupo de niños cuyos derechos no dejan de vulnerarse con la finalización del conflicto armado, manteniéndose su vulnerabilidad en tiempo de paz como consecuencia de las dificultades de inserción en las sociedades a las que pertenece su madre. Es evidente, que el infanticidio vulnera el derecho a la vida, que la estigmatización de madres e hijos en las sociedades a las que pertenecen las primeras repercute sobre el derecho a la salud, en principio física (debido a que se les ubica en los márgenes de pobreza), aunque evidentemente con incidencia psicológica. En ocasiones, el tratamiento que se dispensa a estos niños es susceptible de calificarse como de tratos inhumanos o degradantes, en la medida en que se ha documentado que son a su vez víctimas de maltrato y de violaciones y abusos. No está de más recordar en este punto, que con independencia de cuál sea el origen de su nacimiento, todos los niños son titulares de los derechos humanos y del derecho humanitario, por lo que los comportamientos discriminatorios, son contrarios al ordenamiento actualmente vigente. En las páginas que siguen nos detendremos en algunos de los derechos de los que todos los niños son titulares y que se vulneran en relación a los niños que nos ocupan.

\section{Pertenencia al grupo materno y discriminación}

Cuando la mujer violada decide responsabilizarse del cuidado del niño, habitualmente se encuentra con el rechazo de su círculo familiar más próximo así como del grupo o de la comunidad a la que pertenece que pueden no considerar al pequeño como uno de sus integrantes, $\mathrm{y}$ al comportarse de este modo, vulneran la prohibición de discriminar. En este punto nos planteamos dos cuestiones: 1) ¿la prohibición de discriminar es absoluta o existen excepciones?; 2) ¿estaríamos en consecuencia ante uno de los supuestos alcanzados por la prohibición?

En relación a la pregunta formulada en primer lugar, debemos partir de varios elementos: uno, la determinación de quienes son miembros del grupo, lo que está claramente establecido desde hace décadas que supone la confluen-

49 Li QIN, L., «Situating Children of Genocidal Rape...», op. cit., supra nota $n^{\circ} 13$, la transcripción del texto figura en la página 69. 
cia de una identificación individual (autoidentificación) por parte del interesado y otra colectiva del grupo que formula un reconocimiento de la membresía del grupo, si uno de los dos falla, no hay un mecanismo que pueda transformar esta ausencia, siendo la única solución posible la no admisión como miembro del grupo considerado. El Comité de Derechos Humanos fue muy claro en el caso Lovelace contra Canadá, al establecer que la legislación estatal no puede determinar totalmente quienes son miembros, en este caso, de la tribu maliseet. En el caso Kitok contra Suecia, no es la legislación nacional, sino el propio grupo sami quien rechaza considerar miembro del grupo a una persona étnicamente saami debido a que el ahora interesado había perdido esta membresía como consecuencia de su alejamiento del grupo ${ }^{50}$.

Para responder a la cuestión concreta, hemos de volver al caso Kitok contra Suecia, puesto que Iván Kitok deseaba ser considerado sami con el propósito de dedicarse a la crianza del reno, actividad que la legislación sueca restringía exclusivamente a los miembros de este grupo humano, por tratarse de uno de sus elementos fundamentales de su identidad cultural. El Comité entiende que la legislación sueca impide la participación de I. Kitok en la vida cultural Sami, al ser rechazado por el grupo como miembro, lo que no infringe los derechos conferidos por el art. 27 del Pacto, puesto que la existencia de la legislación en cuestión es un medio para asegurar la pervivencia y el bienestar de los sami como grupo ${ }^{51}$. En consecuencia, el Comité de Derechos Humanos de Naciones Unidas, en relación a supuestos de minorías étnicas sobre los que ha tenido la ocasión de pronunciarse, ha establecido que cabe la discriminación siempre que sea la única forma de garantizar la pervivencia de la identidad del grupo humano considerado ${ }^{52}$. Lo que nos conduce a una

50 Vid. Lovelace c. Canada, Communication No. R.6/24, REPORT OF THE HUMAN RIGHTS COMMITEE, U.N. GOAR, 36th. sess, supp. n40, at. 166, UN.Doc.A/36/40, Annex 18 (1977), views adopted 19 diciembre 1977 y Kitok c. Suecia, Communication n. 197/1985, opinión del Comité en UN doc. A/43/40 (1980). En el mismo sentido se ha pronunciado el Tribunal Supremo americano en el asunto Santa Clara Pueblo v. Martínez, en el que declaró que la decisión acerca de quiénes son miembros del grupo es una elemento esencial para su supervivencia como grupo diferenciado. Vid. en https://supreme.justia.com/cases/federal/us/436/49/

51 Kitok c. Suecia, Communication n. 197/1985, opinión del Comité en UN doc. A/43/40 (1980).

52 Son los miembros de los grupos humanos considerados los titulares del derecho a participar en la vida cultural de la comunidad (art. 27 de la Declaración Universal de Derechos Humanos y del Pacto de Nueva York sobre derechos civiles y políticos y artículo 15 del Pacto de Nueva York sobre derechos económicos, sociales y culturales). En este punto no cuestionamos el derecho a practicar los elementos que constituyen su cultura, sino la pertenencia al grupo humano que es titular de este derecho. Se trataría de resolver el equilibrio entre el derecho a la identificación de 
respuesta negativa a la pregunta formulada en primer lugar: no se trata de una prohibición con un alcance absoluto.

Advertimos que el criterio étnico no es el único determinante para identificar a los miembros del grupo (de hecho Iván Kitok era étnicamente sami), de serlo, atentaría contra el principio de no discriminación ${ }^{53}$, por lo que a sensu contrario cabe entender que los niños mestizos (sean fruto de relaciones consentidas o no) no deberían ser excluidos del grupo considerado. Bien es cierto que en las culturas patriarcales, la identidad del grupo se transmite por vía paterna, motivo por el cual no se consideraría en ellas al niño ni tan siquiera como mestizo, sino perteneciente al grupo paterno, el ocupante, el enemigo, en definitiva, el causante de tanto dolor, el genocida. A pesar de lo anterior, el Comité Africano de expertos sobre los derechos y el bienestar de los niños, apunta la necesidad de que los Estados supriman en sus respectivas legislaciones las discriminaciones fundamentadas en el género y estado civil de los progenitores a la hora de transmitir la nacionalidad ${ }^{54}$. Sin embargo, lo cierto es que en la actualidad esas diferencias se mantienen, por lo que en ausencia de identificación del individuo como miembro del grupo étnico no se le considera tal y además, no tiene derecho a participar de la identidad cultural del grupo. Lo que nos lleva al tema de la existencia de discriminaciones toleradas o acciones positivas en este caso en aras a preservar la identidad cultural del grupo.

Aunque la membresía es al grupo lo que la nacionalidad al Estado, será la comunidad o grupo afectados quienes puedan determinar los criterios de establecimiento del vínculo preciso para su pertenencia a aquel. Por lo que la conclusión en este punto no puede ser otra que la determinación por parte del colectivo de los criterios o elementos precisos para determinar la participación individual en él, aunque esta capacidad no es absoluta sino que han de respetarse unos principios, entre ellos, el de no discriminación.

los miembros del grupo y los derechos del niño. Evidentemente, aplicando el principio del interés superior del menor deben prevalecer los derechos del niño sobre el anterior, pero ¿podremos obligar al grupo humano considerado a que acepte como miembro al pequeño? La respuesta que nos aporta el Comité de Derechos Humanos en los supuestos en los que se ha referido a esta cuestión es negativa.

53 En este sentido se ha pronunciado el Comité Africano de expertos sobre los derechos y el bienestar de los niños, en su observación general sobre el artículo 6 de la Carta Africana de Derechos y del Bienestar de los niños, página 55, parágrafo 94, Doc. CAEDBE/OG/02 (2014), puede descargarse íntegramente en http://www.refworld.org/cgi-bin/texis/vtx/rwmain/opendocpdf. pdf? reldoc $=y \&$ docid $=54 \mathrm{db} 21 \mathrm{af} 4$

54 Id. Nota anterior, página 56, parágrafo 95. 
Las reflexiones anteriores podrían ubicarnos en la potencial exclusión del grupo de los niños nacidos de los crímenes sexuales. Esto nos conduce a la pregunta formulada en segundo término (si nos encontramos ante uno de los supuestos alcanzados por la prohibición). Antes de pronunciarnos, debemos considerar varios elementos, entre ellos los términos en los que se pronuncian las normas en materia de Derechos Humanos sobre este punto. Así, la Convención sobre los derechos del niño encuentra una clara inspiración en el Pacto Internacional de Derechos Civiles y Políticos que proclama (art. 24.1) el derecho de todos los niños «sin discriminación alguna por motivos de raza, color, sexo, idioma, religión, origen nacional o social, posición económica o nacimiento, a las medidas de protección que su condición de menor requiere, tanto por parte de su familia como de la sociedad y del Estado», la Convención de los derechos del niño añade a esta relación «la opinión política o de otra índole, el origen... étnico..., los impedimentos físicos..., o cualquier otra condición del niño, de sus padres o de sus representantes legales» ${ }^{55}$.

Pareciera que no es posible adoptar medidas que diferencien entre niños por motivo alguno, pero es cierto que existen ordenamientos en los que se distingue entre hijos matrimoniales y no matrimoniales, como ha puesto de relieve, entre otros, el Comité africano de expertos sobre derechos y bienestar de los niños y, recordemos, que en el caso que nos ocupa, nos encontramos ante estos últimos, ya sea porque son hijos de mujeres solteras o porque sin serlo, el padre no es el esposo.

Sin embargo, los derechos del niño apuntan en la dirección contraria a la que nos conduce la idea recién indicada. Así, el Comité de Derechos Humanos de Naciones Unidas, en su observación general número 17, afirma la necesidad de que los informes estatales expresen «la forma en que la legislación y la práctica garantizan que las medidas de protección tengan por objeto eliminar la discriminación en todas las esferas, incluido el derecho sucesorio, en particular entre niños nacionales y extranjeros o entre hijos legítimos e hijos ilegítimos $»^{56}$. Lo que coincide con la jurisprudencia del Tribunal Europeo de Derechos Humanos, en la que se encuentra claramente establecido el tratamiento igualitario entre todos los hijos. Bien es cierto que la argumentación

55 La Convención Internacional sobre la eliminación de todas las formas de discriminación racial, por su parte, mantiene la raza y el color, sustituyendo los demás motivos por el «linaje u origen nacional o étnico».

56 Se trata de la Observación General n ${ }^{\circ} 17$ del Comité de Derechos Humanos, sobre los derechos del niño (art. 24), adoptada en el trigésimo quinto periodo de sesiones, 1989. 
que le sirve al tribunal Europeo para concluir de este modo es la apreciación de un tendencia nítida hacía el tratamiento igualitario entre los hijos matrimoniales y los que no lo son en los Estados miembros del Consejo de Europa, aunque sabemos que esta no es una realidad extrapolable a todos los Estados que conforman la sociedad internacional actual. De todos modos, en la Sentencia en el caso Mazurek el Tribunal Europeo ha afirmado que en la situación actual «únicamente razones muy importantes podrían llevar a considerar compatible con el Convenio una distinción basada en el nacimiento fuera del matrimonio» ${ }^{57}$.

Por tanto, de la jurisprudencia del Tribunal Europeo no ha de desprenderse la imposibilidad de introducir tratamientos diferenciados entre hijos matrimoniales, pues en el asunto Fabris contra Francia, ha afirmado que su función es determinar si la distinción fundamentada en una norma de derecho interno tiene una justificación objetiva y razonable, en cuyo caso su aplicación no tendrá como consecuencia la vulneración del artículo 14 del Convenio Europeo $^{58}$. Del mismo, existen razones muy importantes - por utilizar la terminología empleada por el Tribunal- en las normas de sucesión a la Corona en algunos Estados, en la medida en que se trata de normas específicas para la Jefatura del Estado quedan al margen de la aplicación indicada por el Tribunal ${ }^{59}$.

Bien es cierto que las cuestiones acerca de las que se ha pronunciado el Tribunal, con carácter general, se refieren a la no discriminación en los derechos sucesorios, pero el argumento fundamental es la igualdad entre los hijos, que resulta aplicable en Europa con a otros supuestos de trato diferenciado

57 Sentencia de 1 de febrero de 2000 del Tribunal Europeo de Derechos Humanos (sección tercera) en el asunto Mazurek c. Francia (demanda $n^{\circ}$ 34406/1997), la cita del texto se encuentra en el parágrafo 49.

58 Es la Sentencia de 7 de febrero de 2013, en el asunto Fabris c. Francia (demanda n ${ }^{\circ}$ 16574/08).

59 Así, en el caso de Mónaco, el mismo Tribunal de Estrasburgo, en 2015, si bien no se pronuncia sobre la existencia o no de discriminación en este punto, puesto que el caso se refiere a la vulneración de otro derecho, se refiere como uno de los textos relevantes para la solución del caso en presencia la Constitución monegasca, cuyo artículo 10 establece dos elementos cuestionables, pero uno de ellos nos resulta muy interesante para este trabajo: 1) la sucesión al Trono del Principado de Mónaco solamente se produce entre herederos directos y legítimos del Príncipe reinante; y, 2) se aplica el régimen de primogenitura con preferencia del varón sobre la mujer en la misma línea de parentesco (Sentencia de la Gran Sala, de 10 de noviembre de 2015, en el asunto Couderc y Hachette Filipacchi associés c. Francia (demanda n ${ }^{\circ}$ 40454/07), parágrafo 42, página 15). Encontrándonos aquí ante una doble discriminación: primero, entre hijos matrimoniales y los que no lo son; y, después, discriminación de género [los criterios de sucesión a la Corona no son novedosos, se encuentran entre otras en la Constitución española (art. 57), no se refiere a «hijos legítimos», ciertamente, aunque en el momento en el que se redactó no se entendía de otro modo]. 
entre hijos matrimoniales y los que no lo son, como el que nos ocupa ${ }^{60}$. Por otra parte, según el Tribunal Europeo, el niño se inserta por el hecho del nacimiento en la familia en la que ha nacido, exista o no el vínculo matrimonial, indicando la responsabilidad del Estado en que se garantice la protección jurídica que permita la integración del niño en la familia ${ }^{61}$. Por tanto, la incorporación en la familia implica la inserción social y en cuanto tal, de aquí debería desprenderse la pertenencia al grupo humano al que pertenece la madre.

En algunos lugares, como en el norte de Uganda, a la discriminación que sufren estos niños, se suma la discriminación de género, pues las comunidades humanas son más reacias a aceptar a los niños que a las niñas porque los primeros (al alcanzar una edad determinada) heredan un terreno en el que instalarse, mientras las familias de las segundas reciben una dote cuando contraen matrimonio, por lo que resulta más ventajoso que recibir a varones ${ }^{62}$.

En un ámbito general el Comité de Derechos Humanos de Naciones Unidas establece que «todo niño, sin discriminación alguna por motivos de raza, color, sexo, idioma, religión, origen nacional o social, posición económica o nacimiento, tiene derecho a las medidas de protección que su condición de menor requiere, tanto por parte de su familia como de la sociedad y del Estado» ${ }^{63}$. Al hilo de esta afirmación hemos de plantearnos cuáles son esas

60 Ver las Sentencias del Pleno del TEDH de 13 de marzo de 1979, asunto Marckx c. Bélgica (demanda ${ }^{\circ}$ 6833/74), de 28 de octubre de 1987 en el asunto Inze c. Austria (demanda n ${ }^{\circ}$ 8695/79); de 1 de febrero de 2000 del Tribunal Europeo de Derechos Humanos (sección tercera) en el asunto Mazurek c. Francia (demanda n ${ }^{\circ}$ 34406/1997); de 13 de julio de 2000 de la Gran Sala, en el caso Elsholz contra Alemania, demanda n 25735/1994; de 13 de diciembre de 2007, en el asunto Emonet y otros c. Suiza (sección primera), demanda n ${ }^{\circ} 39051 / 2003$; de 28 de mayo de 2009 (sección $5^{\text {a }}$ ), asunto Brauer contra Alemania (demanda n $\left.{ }^{\circ} 3545 / 2004\right)$ ), de la Gran Sala o de 7 de febrero de 2013, en el asunto Fabris c. Francia (demanda $n^{\circ} 16574 / 08$ ).

61 El Tribunal Europeo de Derechos Humanos ha expresado la idea indicada en el texto en la Sentencia de 13 de julio de 2000, de la Gran Sala, en el caso Elsholz contra Alemania, demanda $\mathrm{n}^{\circ}$ 25735/1994; y, posteriormente en la Sentencia de 13 de diciembre de 2007, en el asunto Emonet y otros c. Suiza (sección primera), demanda n n $^{3}$ 9051/2003.

62 OKIROR, S., «En Ouganda, le combat continue pour les enfants nés de la guerre», en http:// www.irinnews.org/fr/report/101725/en-ouganda-le-combat-continue-pour-les-enfantsn\%C3\%A9s-de-la-guerre También en el caso de Ruanda ocurre esta discriminación entre las hijas y los hijos nacidos como consecuencia de la violación de sus madres. Ver en este sentido: JonES, S., «Like a Tree without Branches: Children Born of Genocide Rape», http://survivors-fund.org.uk/wp-content/uploads/2013/09/Like-a-Tree-without-Branches.pdf

63 Es el parágrafo quinto de la Observación general $n^{\circ} 18$ sobre la No discriminación aprobada en el $37^{\circ}$ periodo de sesiones (1989) por el Comité de Derechos Humanos, puede verse en http:// tbinternet.ohchr.org/_layouts/treatybodyexternal/Download.aspx?symbolno=INT\%2fCCPR $\% 2 \mathrm{fGEC} \% 2 \mathrm{f} 6622 \&$ Lang=en 
medidas de protección imprescindibles, aunque resulta evidente que las cuestiones que nos ocupan, en la medida en que se relacionan con el derecho a la vida o afecta a la dignidad inherente al ser humano, han de verse alcanzadas por ellas.

A diferencia de los hijos de relaciones consentidas con nacionales enemigos, en este caso, a la discriminación social que sufren estos niños se une la familiar así como en la mayoría de los casos, el rechazo por parte de sus entornos más próximos debido a que las víctimas de esta materialización del genocidio o del crimen de guerra son, por una parte, clara y directamente, la mujer violada; y, por otra la comunidad a la que pertenece, por lo que la estigmatización alcanzará por extensión a su familia. Bien es cierto también que, el ser hijo de relaciones consentidas no evita necesariamente el rechazo familiar $y$, en todo caso, han tenido que sobrellevar la estigmatización de la que eran objeto en primera persona por ser hijos del enemigo y la de sus madres, que como las tondues en Francia, tampoco lo tuvieron fácil ${ }^{64}$. Sí parece claro que los hijos de los crímenes sexuales han podido ser víctimas de un mayor número de abandonos y que el comportamiento de sus madres puede estar condicionado por la experiencia traumática en la que encuentran su origen estos niños, cuya superación y olvido resulta mucho más complicado si tienen un recuerdo constante de aquellos luctuosos hechos.

Por otra parte, la Recomendación general $n^{\circ}$ XXIX relativa a la discriminación basada en la ascendencia, aprobada por el Comité para la eliminación de la discriminación racial en su sexagésimo primer periodo de sesiones (2002), a pesar de su denominación, no nos sirve a los efectos que nos proponemos, puesto que aunque se centra en «la discriminación basada en 'la ascendencia'», se refiere a la «discriminación de miembros de diversas comunidades basada en tipos de estratificación social como la casta y sistemas análogos de condición hereditaria que anulan o reducen el disfrute por esas personas, en pie de igualdad, de los derechos humanos». Aquí no nos estamos refiriendo a la estratificación social, sino a la licitud o no de la discriminación de la que son objeto los niños nacidos de los crímenes sexuales cometidos en tiempos de conflicto, que permanecen durante su infancia y su época adulta por el hecho de su concepción.

En este punto, la respuesta del Derecho ha de ser negativa: inadmitiendo ese tipo de discriminaciones, especialmente en la esfera nuclear de los dere-

64 Uninteresantevídeosobreestacuestión enhttps://www.youtube.com/watch?v=_2F86GWEMrM 
chos en los que los menores han de ser objeto de protección. Sin embargo, aunque en Europa se haya detectado una clara tendencia hacia el tratamiento igualitario entre hijos matrimoniales y los que no lo son, esa misma evolución no ha seguido en todos los lugares del mismo modo. El caso de la Carta africana sobre los derechos y el bienestar de los niños es buena muestra de ello (art. 18), pues si bien no incorpora una afirmación semejante a la que venimos indicando, señala como única referencia a los hijos no matrimoniales la siguiente: «Ningún niño será privado de sustento como consecuencia del estado civil de sus padres». De aquí podemos desprender que el artículo tercero del mismo texto cuando incorpora el principio de no discriminación por razón, entre otras, de nacimiento no se está refiriendo a este aspecto que nos referimos. A pesar de lo cual, en los informes del Comité africano de derechos del niño y su bienestar, creado en aplicación de la Carta, se muestra la preocupación por el tratamiento discriminatorio en relación a los hijos nacidos fuera del matrimonio, de donde se deduce que sí que se han de ver alcanzados estos niños por la prohibición contenida en el artículo tercero del mismo texto normativo ${ }^{65}$.

En todo caso, aunque apreciemos una tendencia hacia la no discriminación entre los hijos matrimoniales y los que no lo son, el Comité de los Derechos del niño aún se muestra preocupado en algunas de sus observaciones finales en relación al mantenimiento de la desigualdad en este punto, solicitando a los Estados a los que van dirigidas que se esfuercen por adoptar una legislación igualitaria ${ }^{66}$. Por lo demás, legislar en el ámbito de los afectos o los desafectos, siempre es muy arriesgado y convengamos que, en estos casos, el derecho debería ir acompañado de otros instrumentos que permitieran la plena integración de los menores en la sociedad materna, por muy dura que hubiera sido la represión protagonizada por el grupo al que perteneciera el padre biológico del pequeño.

65 Ver por ejemplo, las observaciones finales respecto de Guinea, en http://www.acerwc.org/download/concluding_observations_guinea/?wpdmdl=8745 , Burkina Fasso: http://www.acerwc.org/ download/concluding_observations_burkina_faso/?wpdmdl=8740 ; o, se felicita por comprobar que Ruanda ha eliminado la discriminación entre hijos matrimoniales y no matrimoniales: http://www.acerwc.org/download/concluding_observations_rwanda/?wpdmdl=8753. También, con carácter general, la observación general sobre el artículo 6 de la Carta Africana de Derechos y del Bienestar de los niños..., op. cit., supra nota $\mathrm{n}^{\circ} 53$.

66 Es el caso, entre otros, de las observaciones finales sobre los informes periódicos segundo y tercero combinados de Timor-Leste, de 30 de octubre de 2015, Doc. CRC/C/TLS/CO/2-3; de Gambia, de 20 de febrero de 2015, Doc. CRC/C/GM/B/CO/2-3, Marruecos, de 14 de octubre de 2014, Doc. CRC/C/MA/R/CO/3-4. 


\section{Protección de la familia}

Según la Convención sobre los derechos del niño, los menores deben crecer en el seno de una familia, que es la responsable de su «integración social primaria ${ }^{67}$, el Estado, por su parte, ha de adoptar medidas para garantizar ese entorno protector. Lo anterior no debe entenderse en el sentido de que exista el derecho a convivir con la familia biológica ${ }^{68}$, en la mayoría de los casos será así, pero existen supuestos en los que esta unidad se verá sustituida por una familia adoptiva, de acogida o, de no ser posible ninguna de ellas, por las instituciones públicas.

En más casos de los que nos gustaría conocer ni la mujer que ha sido violada por el ejército enemigo ni el hijo fruto de ella han podido contar con el entorno protector que les proporciona la familia, siendo expulsadas de estos núcleos para evitar la estigmatización que derivaría para ellos ${ }^{69}$. En consecuencia, debieron salir adelante con sus hijos sin apoyo alguno de sus familias, ni de sus comunidades, iniciando así el camino hacia la pobreza.

Que la familia es la unidad básica de la sociedad no es ninguna novedad, lo proclamó la UNESCO en 1947, en su informe sobre los problemas de los niños víctimas de la guerra ${ }^{70}$ y veinte años más tarde, la Asamblea General de las Naciones Unidas ${ }^{71}$. Así, el entorno familiar es protector con carácter gene-

67 Son los términos en los que se expresa el apartado decimosegundo de las Directrices de las Naciones Unidas para la prevención de la delincuencia juvenil, conocidas como «Directrices de Riad», aprobadas y proclamadas por la Asamblea General en su resolución 45/112, de 14 de diciembre de 1990. Pueden leerse en http://www.ohchr.org/SP/ProfessionalInterest/Pages/ PreventionOfJuvenileDelinquency.aspx

$68 \mathrm{La}$ Corte Interamericana de Derechos Humanos en la Sentencia de 27 de abril de 2012, en el caso Forneron e hija contra Argentina (parág. 119, p. 37), afirma que «a la familia que todo niño y niña tiene derecho es, principalmente, a su familia biológica el niño tiene derecho a una familia, preferentemente biológica».

69 Según Wing, A.K. y MerChán, S., «Rape, Ethnicity and Culture...», op. cit., supra nota nº 33, p. 24, afirma que en determinados contextos, como el que ofrecen los musulmanes de Bosnia, la familia de la mujer violada desciende en la posición social de la comunidad como consecuencia de este hecho, efecto que los miembros de la familia pueden pretender evitar desentendiéndose del niño o incluso expulsando a la mujer violada, aunque ninguno de estos comportamientos vuelven a ubicarle en la posición social que tenía antes de la violación, si este hecho es conocido por quienes le rodean.

70 Vid. supra en nota 1 la referencia a los dos informes elaborados sobre esta cuestión, uno, el general, de 5 de noviembre de 1947 y en segundo, sobre la particular situación de los niños polacos un año después.

71 En concreto en la Declaración sobre el Progreso y el Desarrollo en lo social (1969), aprobada en la resolución 2542 (XXIV), de la Asamblea General de Naciones Unidas, de11 de diciembre de 
ral pero muy especialmente en la situación que nos ocupa puesto que ayudan a sobrevivir a la mujer y al niño. La UNESCO en aquel informe va más allá afirmando que es la «cellule nourricière de l'enfant et garant de son équilibre affectif $\gg^{72}$. En consecuencia, es imprescindible para la salud tanto física como psicológica de los menores.

En el ámbito latinoamericano, el Protocolo de San Salvador manifiesta en su artículo 16 la titularidad de los niños respecto del derecho a «medidas de protección por parte de su familia, de la sociedad y del Estado». En este punto la Corte Interamericana de Derechos Humanos, considera que «la familia debe proporcionar la mejor protección de los niños contra el abuso, el descuido y la explotación ${ }^{73}$. La responsabilidad del Estado se reduce a adoptar las medidas necesarias para que la familia pueda desarrollar del mejor modo posible las funciones que tiene en la sociedad, además, debe garantizar que ese núcleo social respeta los derechos establecidos en la Convención sobre los derechos del niño.

Si todo funciona adecuadamente, el papel del Estado se reduce a lo antedicho, si por el contrario, la familia no puede cumplir las funciones que tiene atribuidas, las Directrices de Riad establecen que el Estado debe «recurrir a otras posibles modalidades de colocación familiar, entre ellas los hogares de guarda y la adopción, que en la medida de lo posible deberán reproducir un ambiente familiar de estabilidad y bienestar y, al mismo tiempo, crear en los niños un sentimiento de permanencia» ${ }^{74}$. En consecuencia, el Estado cuenta con un papel subsidiario respecto de la familia puesto que sólo es relevante su desempeño en ausencia de una familia responsable del menor. Es cierto que la

1969, cuyo artículo cuarto contiene la siguiente redacción: «La familia, como unidad básica de la sociedad y medio natural para el desenvolvimiento y bienestar de todos sus miembros, especialmente los niños y los jóvenes, debe ser ayudada y protegida para que pueda asumir plenamente sus responsabilidades en la comunidad». Vid. http://www.un.org/es/comun/docs/?symbol=A/ RES/2542(XXIV)\&Lang=S\&Area=RESOLUTION Se trata de una afirmación reiterada por el artículo 18 de la Carta africana de los derechos y el bienestar de los niños.

72 Vid. supra nota 1, capítulo II, página 9 del informe general (los problemas de los niños víctimas de la guerra).

73 El texto transcrito en el texto se encuentra en el parágrafo 66 de la Opinión consultiva C-17 de 2002, de 28 de agosto de 2002, solicitada por la Comisión Interamericana de Derechos humanos sobre la condición jurídica y los derechos humanos del niño.

74 Es el apartado 14 de las Directrices de las Naciones Unidas para la prevención de la delincuencia juvenil, conocidas como «Directrices de Riad», aprobadas y proclamadas por la Asamblea General en su resolución 45/112, de 14 de diciembre de 1990. Pueden leerse en http://www.ohchr. org/SP/ProfessionalInterest/Pages/PreventionOfJuvenileDelinquency.aspx 
Convención sobre los derechos del niño no se expresa tan claramente como estas Directrices, pues se refiere tan solo a la separación de los progenitores (no al concepto de familia, que resulta más extenso que éste) contra la voluntad de estos últimos, haciendo depender esa separación del interés superior del menor, que aunque no lo mencionan las Directrices de Riad, se desprende del contexto que esta ha de ser la razón de la separación. En el mismo sentido se pronuncia la Corte Interamericana de Derechos Humanos en la opinión consultiva precitada (parágrafo 77).

En todo caso, la ausencia de familia en sentido absoluto, es decir, cuando se produce un de abandono o entrega para adopción, provoca en los hijos de los crímenes sexuales daños añadidos, en ocasiones porque terminan siendo niños de la calle, si el Estado carece de las estructuras necesarias para evitarlo y en otras, por las dificultades de procurar una familia adoptiva. Existe escasa información sobre los primeros, debido a que los informes que presentan los Estados partes al Comité de los derechos del niño no aluden a esta cuestión y, cuando lo hacen, es solo superficialmente. Es evidente que aunque estos niños no sean expresamente mencionados en la Convención son titulares de los derechos contenidos en ella, siendo responsabilidad de los Estados parte en este tratado internacional, adoptar las medidas necesarias para mejorar las condiciones de estos menores vulnerables ${ }^{75}$. En este sentido, recordemos que, por ejemplo en el caso ruandés, los tutsis entendían que los niños nacidos de estas violaciones eran hutus, perteneciendo al grupo étnico perpetrador del genocidio del que habían sido víctimas. Esa semejanza étnica entre el agresor y el recién nacido aboca al niño a ser objeto de $\operatorname{abusos}^{76}$ en la comunidad a la que pertenece su madre, si al menos cuenta con un entorno familiar éste le protegerá o al menos hará cuanto esté en su mano para evitar esas experiencias negativas, pero si se trata de un niño de la calle parece que el futuro se torna mucho más sombrío en este aspecto.

En ocasiones, la adopción internacional es alentada por las autoridades estatales, como en el caso de Bangladesh, cuyo Primer Ministro afirmó «Plea-

75 Sobre las circunstancias en las que sobreviven los niños de la calle, véase el Informe de la Alta Comisionada de las Naciones Unidas para los Derechos Humanos sobre la protección y promoción de los derechos humanos de los niños que trabajan y/o viven en la calle, de 11 de enero de 2012, Doc. A/HRC/19/35.

$76 \mathrm{Vid}$. Carpenter, R.Ch., «Assessing and addressing the needs of children born of forced maternity», trabajo presentado a la Conferencia Internacional de niños afectados por la Guerra, celebrada en Winnipeg, Canadá, entre los días 11 y 17 de septiembre de 2000, puede descargarse en http:// web.tiscali.it/humanrights_it/ing/parttwof.htm 
se send away the children who do not have their father's identity. They should be raised as human beings with honor. Besides, I do not want to keep those polluted blood in this country» ${ }^{77}$, lo que indica la conveniencia de la adopción internacional de estos niños. Las misioneras de la caridad de la Madre Teresa para evitar los abortos convencieron a las mujeres que no desearan a los bebes se los dejaran para su cuidado, con el propósito de darlos en adopción a familias occidentales. El gobierno también animó a agencias internacionales de adopción para que los considerasen adoptables. Inicialmente las autoridades islámicas protestaron por esta situación debido a que el destino de los niños eran Estados cristianos, pero finalmente no obstaculizaron la puesta en práctica de la idea. La legislación nacional impedía la adopción de niños bangladeshies por nacionales extranjeros, por lo que debió modificarse puntualmente con el propósito de permitirlas durante el periodo postconflicto y respecto de estos hijos de los crímenes de guerra. Que el tema de las adopciones es sensible en Bangladesh se evidencia también en relación a su consideración de parte en la Convención sobre los derechos del niño, dado que en el momento de manifestar su consentimiento en obligarse por ella depositó una reserva que precisamente pretende modificar los efectos del artículo 21 de este Tratado Internacional (referido a la adopción), con el objeto de aplicarlo conforme a lo establecido en sus leyes y prácticas ${ }^{78}$.

Algo parecido ocurrió en Bosnia, cuya autoridad islámica en Fatwa on Children Born by Raped Women in Bosnia-Herzegovina ${ }^{79}$ pedía que se aplicaran las medidas oportunas y se realizaran los esfuerzos necesarios para integrar lo mejor posible a los niños nacidos como consecuencia de los crímenes sexuales producidos durante el conflicto, pues se oponía tanto a la adopción como a «the creation of special shelters and registers or records to avoid future

77 En D’CostA, B., «Tragic Silence over Bangladesh's Babies of War 1971», en South Asia Citizens Web: http://www.sacw.net/article581.html. En todo caso, al parecer, según la misma autora, se ayudó a las mujeres que quisieran abortar a hacerlo en clínicas auspiciadas por Bangladesh Central Organisation for Women's Rehabilitation in Dhaka y otras localidades.

$78 \mathrm{Vid}$. en http://indicators.ohchr.org/. Reserva que, en las Observaciones finales sobre el quinto informe periódico de Bangladesh, del Comité de los Derechos del Niño, de 29 de octubre de 2015, Doc. CRC/C/BGD/CO/5, valora positivamente el hecho de que las autoridades bangladesíes estén estudiando retirar. Retirada que había indicado en los mismos términos años antes, pues este mismo comentario figura en las observaciones finales unos años antes ( 26 de junio de 2009), Doc. CRC/C/BGD/CO/4.

79 Vid. Daniel-Wrabetz, J., «Children Born of War-Rape in Bosnia-Herzegovina and the Convention on the Rights of the Child», en CARPENTER, R.C., Born of War: Protecting Children of Sexual Violence Survivors in Conflict Zones, Kumarian Press, Sterling (Virginia), 2007, pp. 21 y ss. 
stigmatization - the children's real identities should be kept secret and they should not be given up for adoption in order to protect them from threats like slavery, abuse and trafficking» ${ }^{80}$. Sin embargo, según las informaciones publicadas, lo cierto es que estas indicaciones no fueron efectivas, pues aunque el Gobierno bosnio prohibió las adopciones de los niños nacidos de violaciones de guerra con la esperanza de que fueran aceptados por sus madres o por otras familias tras el conflicto ${ }^{81}$, obtuvo escaso éxito en este empeño debido a la preferencia de los padres adoptivos por recién nacidos, y no podemos olvidar que concluida la contienda, cuando se normalizó el sistema de adopciones, los niños que nos ocupan ya habían superado esa primera infancia.

\section{Derecho a la identidad y a la nacionalidad}

Una de las cuestiones a abordar desde la perspectiva de los derechos humanos es el derecho a la identidad de los menores y a su nacionalidad. En este sentido, hemos de adoptar como punto de partida el artículo 24.2 del Pacto Internacional de derechos civiles y políticos, conforme al cual todos los niños tienen derecho a su inscripción registral inmediatamente después de su nacimiento, habiéndose consolidado como un derecho humano fundamental ${ }^{82}$. Esto implica el derecho a un nombre, que en ocasiones, debido a su origen es una denominación que recuerda el dolor sufrido por la madre, y de no ser así, el apelativo por el que se les suele conocer sí que resulta despectivo. Por ejemplo, K. Theidon en su artículo sobre Perú, nos muestra índices de esta situación: hay madres que eligen para los hijos nacidos de violaciones nombres que les recuerdan su dolor, de modo que quedan estigmatizados solo por la denominación elegida. Además, en sociedades tradicionales en las que contamos

80 Mochmann, I.C. y Larsen, S.U., «The Human Rights of Children...», op. cit., 35, 2010, 3, pp. 268 y ss. La frase transcrita en el texto se encuentra en la página 283, en referencia a la idea de Daniel-WrabeTZ, J., «Children born of wa...», op. cit., pp. 21-39.

81 LI QIN, L., «Situating Children of Genocidal Rape: Towards Membership in an Ethnic Community», Singapore Law Review, 2003, 23, pp. 45 y ss., especialmente p. 57.

82 Así se pronuncia el Secretario General en su Informe sobre las repercusiones de la privación arbitraria de la nacionalidad en el disfrute de los derechos de los niños afectados, y leyes y prácticas vigentes en materia de accesibilidad de los niños a la adquisición de la nacionalidad, entre otros, del país en el que han nacido, si de otro modo serían apátridas, de 16 de diciembre de 2015 , Doc. A/HRC/31/29, en https://documents-dds-ny.un.org/doc/UNDOC/GEN/G15/286/05/ PDF/G1528605.pdf?OpenElement. 
con dos apellidos (paterno y materno) la coincidencia entre los de la madre y el hijo ya demuestra la realidad de un padre que no quiso reconocerlo ${ }^{83}$, lo que puede contribuir a la marginación del pequeño.

La obligación de inscripción registral inmediata del nacimiento es difícil de cumplir en algunos contextos, como el que proporcionan los conflictos armados, pues las contiendas dificultan necesariamente el acto registral, debido a múltiples factores que, por evidentes, no merece reproducir aquí. En tiempo de paz, también hay lugares en los que la práctica resulta deficiente, tomemos como ejemplo, las observaciones remitidas por parte del Comité africano de los derechos del niño y su bienestar a Uganda y a Egipto, en las que se solicita que se multipliquen los esfuerzos por garantizar el registro de los nacimientos producidos $^{84}$. La ausencia de registro ubica al niño en el limbo legal en el que se traduce su inexistencia jurídica, pues carecen de identidad, de nacionalidad y de la capacidad de acceso a todos aquellos servicios o prestaciones estatales para las que se precise la identificación individual, principalmente a la de educación y sanidad que pudieran existir ${ }^{85}$.

En el convencimiento de que la inexistencia de inscripción registral vulnera derechos fundamentales del niño, el Comité de los derechos del niño ha afirmado su preocupación por el hecho de que esta ausencia, siendo más frecuente en contextos de conflictos armados, se produzca en otros lugares. Así lo ha hecho por ejemplo en las observaciones finales a República Dominicana, subrayando su preocupación por el hecho de que «en 2012 una quinta parte de los niños menores de 5 años, en su mayoría de familias que vivían en la pobreza, no tuviera un certificado de nacimiento. Si bien toma nota del proyecto

83 Vid. Theidon, K., «Ocultos a plena luz...», supra en nota $\mathrm{n}^{\circ} 17$. Las referencias indicadas en el texto se encuentran en las páginas 163-170.

$84 \mathrm{Vid}$. en http://www.acerwc.org/download/concluding_observations_uganda/?wpdmdl=8752; http://www.acerwc.org/download/concluding_observations_egypt/?wpdmdl=8743 En su observación general sobre el artículo 6 de la Carta Africana de los Derechos y el bienestar del niño, el mismo comité indica que según un informe de Unicef de 2013, 230 millones de niños de menos de cinco años no fueron registrados cuando nacieron. Calculándose que veinte millones de niños en África subsahariana carecen de certificados de nacimiento. La observación general [Doc. CAEDBE/OG/02 (2014)], puede verse en http://www.refworld.org/cgi-bin/texis/vtx/rwmain/opendocpdf.pdf? reldoc $=y \&$ docid $=54 \mathrm{db} 21 \mathrm{af} 4$

85 OKIROR, S., «En Ouganda, le combat continue pour les enfants nés de la guerre», en http:// www.irinnews.org/fr/report/101725/en-ouganda-le-combat-continue-pour-les-enfantsn\%C3\%A9s-de-la-guerre. En el caso de Ruanda, el artículo 7 de su Constitución establece «Les personnes d'origine rwandaise et leurs descendants ont le droit d'acquérir la nationalité rwandaise, s'ils le demandent». En consecuencia, la madre transmite igualmente la nacionalidad, de donde se desprende que los hijos de madre ruandesa tienen esa nacionalidad. 
piloto en curso en cuatro hospitales para remediar la situación, preocupa al Comité que, a pesar de que existen oficinas del registro civil en los hospitales, muchos niños siguen sin estar inscritos en él. ${ }^{86}{ }_{\gg}$ Lo anterior pone de relieve la necesidad de campañas que conciencien a la población de la inscripción a los niños recién nacidos, junto, evidentemente con las facilidades en el cumplimiento de esta obligación cuya supervisión y garantía es responsabilidad de los Estados. En todo caso, convengamos en que esta ausencia resulta más frecuente entre los niños nacidos en campos de trabajo en los que puede haberse internado a las madres como una manera de forzarlas a llevar a término su maternidad no deseada, aunque no es exclusiva de este tipo de situaciones.

Como indica el Comité africano de expertos sobre los derechos y el bienestar del niño en la decisión sobre los niños de ascendencia nubia ${ }^{87}$, de la ausencia de inscripción registral deriva el desconocimiento de derechos de propiedad, motivo por el cual se les considera ocupantes ilegales de sus tierras, provoca el rechazo a dotarles de servicios públicos como el agua, el acceso a la educación o la salud, lo que conduce necesariamente a los niños de ascendencia Nubia a la pobreza así como a la reducción de la esperanza de vida. El Comité de los derechos del niño ha incidido sobre esta cuestión en las Observaciones finales sobre los últimos informes remitidos por Kenia ${ }^{88}$. En

86 Es el parágrafo 25, página 6, de las observaciones finales sobre los informes periódicos tercero a quinto combinados de la República Dominicana, de 6 de marzo de 2015, Doc. CRC/C/DOM/ CO/3-5. En el caso de Ruanda, su preocupación en este punto se refiere exclusivamente a los niños de minorías étnicas o indígenas (parág. 73, p. 29, de las observaciones finales a Ruanda, de 1 de julio de 2004, Doc. CDC/C/15/Add.234), también en el caso de Colombia se refiere a los niños indígenas y desplazados (parág. 30, p. 10, de las observaciones finales sobre los informes periódicos cuarto y quinto combinados de Colombia, de 6 de marzo de 2015, Doc. CRC/C/ $\mathrm{CO} / \mathrm{L} / \mathrm{CO} / 4-5)$, en el de Rumanía afecta especialmente a niños romaníes, pero no de forma exclusiva, pues se contempla también en «los niños de la calle, los recién nacidos abandonados en hospitales y los niños nacidos en su hogar y en otros entornos» (parág. 35, p. 9 de las observaciones finales a Rumanía, de 30 de junio de 2009, Doc. CRC/C/ROM/CO/4); en el de Guatemala afecta a zonas rurales y remotas, especialmente a los pueblos indígenas (parág. 51, p. 9 de las observaciones finales a Guatemala de 25 de octubre de 2010, Doc. CRC/C/CGTN/ $\mathrm{CO} / 3-4)$, entre otros muchos ejemplos.

87 Ver las Observaciones finales sobre los informes periódicos tercero a quinto combinados de Kenya, de 21 de marzo de 2016, Doc. CRC/C/KE/N/CO/3-5. También y muy especialmente la Décision 002/COM/002/09 IHRDA\&OSJI (au nom des enfants d'ascendance nubienne au Kenya) v. Kenya, puede descargarse en http://www.ihrda.org/wp-content/uploads/2012/04/ ACERWC-nubian-decision-pamphlet-Fr-2012-website-download.pdf

88 Aunque amplía el ámbito de preocupación no solo a los niños de origen nubio, sino también a los refugiados «los niños makonde, los niños originarios de Somalia que residen en Kenya, los niños cuyas madres están privadas de libertad y los niños intersexuales, tengan dificultades para 
consecuencia, la vulneración de la obligación de inscripción registral implica la violación de todos los derechos recién mencionados, recogidos en los textos generales de derechos humanos, en la Convención de los derechos del niño y en la Carta africana sobre los derechos y el bienestar del niño.

El derecho a la identidad y la nacionalidad ${ }^{89}$ van unidos, aunque puedan suscitar más problemas en aquellos lugares en los que el criterio de atribución de nacionalidad es el ius sanguinis paterno ${ }^{90}$, del mismo modo que la pertenencia al grupo humano considerado la transmite el padre. En este sentido, las palabras de P.A. Weitsman son muy clarificadoras, conforme a las cuales «Once born, the identity of the war babies is inextricably linked to their rapist fathers. This link exists even if the paternal identity is completely unknown, which is usually the case because either the survivor did not know the rapist or because so many men raped the mother that establishing paternity without genetic testing is impossible. The child's identity is tied to the father, even if the child never meets the father and even if the child's mother cares for and raises the child $\gg^{91}$.

En esta situación nos encontraríamos con problemas de atribución de nacionalidad en la medida en que el niño es hijo del enemigo, que salvo en los supuestos de conflicto armado interno, será extranjero. No es necesario recordar que en el supuesto en presencia no hay reconocimiento de filiación por parte del padre biológico, motivo por el cual tampoco habrá nacionalidad paterna. La Convención para erradicar los casos de apatridia de 1961 establece que «todo hijo nacido dentro del matrimonio en el territorio de un Estado contratante cuya madre sea nacional de ese Estado, adquirirá en el momento del nacimiento la nacionalidad de dicho Estado si de otro modo sería apátrida», sin embargo, esta solución no es suficiente para el caso que nos ocupa, puesto que los nacidos no son matrimoniales.

conseguir la inscripción de los nacimientos», lo que a su vez niega la nacionalidad puesto que ésta se deriva de aquel acto registral. Ver las Observaciones finales sobre los informes periódicos tercero a quinto combinados de Kenya, de 21 de marzo de 2016, Doc. CRC/C/KE/N/CO/3-5.

89 El derecho a la nacionalidad se encuentra en la Declaración Universal de Derechos Humanos (art. 15) y reconocido en tratados internacionales de Derechos Humanos de alcance general o regional, además, en lo que a nosotros nos interesa, en el párrafo primero del artículo 7 de la Convención sobre los Derechos del niño.

90 Sobre la nacionalidad de los niños puede verse, entre otros, VIÑAS FARRÉ, R., «Nacionalidad y derechos del niño», en AA.VV., La protección de los niños en el Derecho internacional y en las relaciones internacionales, Marcial Pons, Madrid, 2010, pp. 57 y ss.

91 Vid. Weitsman, P.A., «The Politics of Identity and Sexual Violence...», op. cit., supra nota ${ }^{\circ}$ 9, p. 566. 
El mismo texto convencional se pronuncia en relación a los niños abandonados, establece (art. 2), al considerarlos nacionales del Estado en el que se encuentran, presumiéndose igualmente la coincidencia de la nacionalidad de los progenitores con la del lugar en el que está. Por su parte, el Informe anual del Alto Comisionado de Naciones Unidas para los Derechos Humanos sobre repercusiones de la privación arbitraria de nacionalidad en el disfrute de los derechos de los niños afectados y leyes y prácticas vigentes en materia de accesibilidad de los niños a la adquisición de nacionalidad, entre otros, del país en el que han nacido, si de otro modo serían apátridas, recuerda que los Estados están obligados a «adoptar todas las medidas apropiadas, tanto en el plano nacional como en cooperación con otros Estados, para garantizar que todo niño tenga una nacionalidad en el momento de su nacimiento» ${ }^{92}$. El motivo de esta necesidad es evitar que sea víctima de discriminación en lo que a medidas protectoras se refiere, en ausencia de una nacionalidad que le ampare a estos efectos.

Desde una perspectiva regional europea, el Tribunal Europeo de Derechos Humanos ha tenido ocasión de pronunciarse acerca de la relevancia del vínculo de nacionalidad, es cierto que no respecto de los niños que nos ocupan, pero sus reflexiones nos resultan de utilidad en este punto. En el asunto Mennesson c. Francia, el Tribunal ha de pronunciarse respecto de la gestación subrogada de nacionales de Estados cuya legislación prohíben esta práctica, y en cuyas oficinas consulares se procedía a negar la inscripción registral de los así nacidos en sus lugares de origen. En este sentido, el Tribunal afirma que la ausencia de reconocimiento de la filiación impide la adquisición de la nacionalidad francesa, su pasaporte, permiso de residencia válido, así como de los derechos derivados del vínculo de nacionalidad bien es cierto que durante su minoría de edad están protegidos ${ }^{93}$. El Gobierno rechaza esta argumentación al considerar que, de conformidad con la legislación francesa, el hijo de un nacional francés será igualmente francés, pudiendo obtener la nacionalidad mediante el reconocimiento de las actas de nacionalidad estadounidense. Pero, el Tribunal realiza una afirmación muy interesante, al considerar que si bien el Convenio Europeo de Derechos Humanos no garantiza el derecho a adquirir una nacionalidad, este vínculo es un elemento de identidad individual, concluyendo que de la negación de la nacionalidad se deriva la vulneración del derecho a la identidad.

92 El texto transcrito en el texto se encuentra en el parágrafo 10 del Informe citado, distribuido el 16 de diciembre de 2015, Doc. A/HRc/31/29.

93 Se trata de la Sentencia de 26 de septiembre de 2014, de la quinta sección en el asunto Mennesson contra Francia, Demanda n ${ }^{\circ}$ 65192/11, parág. 68, pp 25-26. 


\section{4. ¿Existe un derecho a saber quiénes son los padres biológicos?}

Otra de las cuestiones que pueden ocurrir, en el caso de los niños que han sido abandonados, cuando alcanzan su edad adulta es que aspiren a conocer quiénes son sus padres biológicos, es decir, sus orígenes, lo que no se desprende de ninguno de los derechos protegidos y, desde una perspectiva práctica, no es siempre posible. Este deseo no es particular de los niños nacidos como consecuencia de crímenes sexuales, sino en general de quienes han sido adoptados o no conocen a uno de sus progenitores. Si no existen datos sobre cuántos niños encuentran su origen en este tipo de crímenes resulta evidente que carezcamos igualmente de cifras o porcentajes de cuántos de ellos han solicitado información en este punto. Por ello aquí partimos de la consideración de la respuesta que se les daría si tuvieran la curiosidad de realizar este tipo de valoraciones. Además, hemos de considerar del mismo modo que, si ello ocurriera, no habría discriminaciones respecto de otros solicitantes, pues el dato de su origen no puede repercutir en este punto en un sentido u otro.

En todo caso, del estudio de la jurisprudencia del Tribunal Europeo de Derechos Humanos podemos distinguir dos supuestos: uno, cuando desea identificar a esos padres biológicos (que será el niño dado en adopción); otro, cuando tiene sospechas acerca de quién es su padre y desea confirmarlas, en este punto las sospechas serían las que hubiera compartido la madre con él, por lo que el supuesto será de un hijo no matrimonial. En relación al primer supuesto se pronunció el Tribunal Europeo en el asunto Odievre c. Francia. En este caso se trataba de intentar conciliar el interés en el conocimiento de los orígenes del demandante, frente a legislaciones protectoras de la adopción que se fundamentan en el secreto de los progenitores. La Ley francesa $\mathrm{n}^{\circ}$ 2002-93 permite ese secreto del nacimiento si la madre así lo solicita, aunque cabe la reversibilidad en el supuesto de mutuo acuerdo entre la madre y los hijos. La demandante alega que el nacimiento secreto es discriminatorio porque restringe su capacidad de recibir bienes de su madre biológica. El Tribunal en este punto se pronuncia en contra de su pretensión entendiendo la inexistencia de discriminación puesto que el «Or tel n'est pas le cas puisque tous les enfants pour lesquels le secret de naissance a été demandé sont soumis aux mêmes règles pour acceder à la connaissance de leurs origines ${ }^{94}$.

94 Es la Sentencia de 13 de febrero de 2003, en el asunto Odièvre c. Francia (demanda n ${ }^{\circ} 42326 / 98$ ) el texto transcrito se encuentra en el parágr. 52, p. 21. 
En todo caso, el supuesto resuelto por el Tribunal Europeo tiene una finalidad estrictamente económica, pues se vincula claramente con el interés por participar en los derechos sucesorios de los padres biológicos, resultando clara la afirmación del Tribunal en sus justos términos. Se trata de un supuesto jurídicamente y en abstracto, fácil de dilucidar porque nos encontramos entre el interés del hijo de averiguar quiénes son sus padres biológicos, normalmente la madre y el de ésta que no desea ser identificada, que entregó en su día a su hijo a las instituciones públicas con esa condición y que, contactada a solicitud de éste, mantiene su convicción inicial.

Acerca de la segunda hipótesis planteada, consistente en confirmar las sospechas sobre la paternidad, el Tribunal Europeo reconoció, en el asunto Jäggi c. Suiza, que en determinados supuestos, las dudas acerca de si una persona concreta es su padre biológico produce daños morales y físicos ${ }^{95}$, motivo por el cual, deberíamos ponderar el derecho a la salud para decidir sobre la conveniencia o no de la adopción de medidas tendentes a transformar la sospecha en certeza, tanto en un sentido como en el contrario. En el mismo sentido se pronunció en el caso Mikulič contra Croacia, al afirmar que la vida privada incluye el vínculo jurídico entre un hijo no matrimonial y su padre. En consecuencia, «le respect de la vie privée exige que chaucun puisse établir les détails de son identité d'être humain et que le droit d'un individu à de telles informations est essentiel du fait de leurs incidences sur la formation de la personalité» ${ }^{96}$. Así pues, la inacción estatal en la que se traduce la ineficacia de los tribunales acerca de la confirmación de las sospechas de la requirente, vulnera en el caso concreto su derecho a la vida personal, protegido en el artículo 8 del Convenio Europeo.

\section{Conclusiones}

En las páginas precedentes se han intentado evidenciar la difícil situación en la que han de sobrevivir los hijos nacidos de los crímenes sexuales, mostrando que las discriminaciones y diferencias de las que son objeto, que vulneran

95 Es la Sentencia de 13 de julio de 2006, de la tercera sección, en el Aunto Jäggi contra Suiza (demanda $\mathrm{n}^{\circ} 58757 / 00$ ), la idea del texto se encuentra en el parágrafo 40, página 7.

96 El texto transcrito se encuentra en la p. 8, parágrafo 54 de la Sentencia de 7 de febrero de 2002, de la Primera sección del tribunal Europeo, en el asunto Mukulič contra Croacia, demanda $\mathrm{n}^{\circ}$ 53176/99. Esa misma idea se plasmó en la Sentencia del Pleno de 7 de julio de 1989 del mismo Tribunal en el asunto Gaskin contra Reino Unido, demanda nº 10474/83, página 16, parágrafo 39. 
los derechos fundamentales de estos pequeños, que se ven subsistiendo en la pobreza, rechazados por el entorno más próximo, sintiéndose culpables de la durísima situación por la que tuvo que pasar su madre y, probablemente, de las posibles secuelas que ella padezca.

Como se ha señalado antes, si bien han sido concebidos durante un conflicto armado, a diferencia de los otros niños, para los que encuentran su origen en los crímenes sexuales, el dolor y el sufrimiento no termina con la contienda, sino que se mantiene y, en ocasiones, multiplica en la posguerra, la reconstrucción y la reconstrucción de una sociedad duramente abatida por los hechos que han ocurrido en su seno.

Desafortunadamente, parece que hemos aprendido muy poco de los errores cometidos. La lógica nos indica que, cuando finaliza un conflicto armado, hay que aplicar planes de reconciliación en los que se integren también los niños que hayan podido nacer de relaciones entre el vencedor y el vencido, por lo que es necesario preparar no solo a los propios afectados, sino también a las familias y comunidades a las que haya de reintegrarse para evitar la estigmatización de estos niños. Es cierto que es difícil prevenir los comentarios maliciosos o los actos de vandalismo puntuales contra ellos pero el Estado tiene que adoptar todas las medidas necesarias en aras al interés superior de estos menores que gozan de una especial vulnerabilidad frente al resto y, si las medidas preventivas no son eficaces, deberá aplicar aquellas que resulten oportunas con la finalidad de reprimir esos comportamientos.

Tampoco resulta fácil asumir con normalidad la llegada del diferente especialmente en aquellas culturas que consideran que la identidad se transmite por línea paterna, en cuyo caso será como acoger al enemigo en nuestra propia comunidad, máxime si se piensa que la maldad de los ejércitos invasores la heredan los hijos concebidos de este modo. En estos casos, el mestizaje implica la consideración del niño como perteneciente al grupo paterno que ha sido el agresor, y en este caso, es el enemigo genocida. En todo caso, no parece casual el olvido de estos niños sistemáticamente en los procesos de reconciliación.

La ubicación del foco de atención en las que son las verdaderas víctimas de los crímenes sexuales, las mujeres violadas, ha tenido como consecuencia la ignorancia de los niños que nacieron como consecuencia de ellos. De este modo, es evidente que hay planes postconflicto que tienen en cuenta a las primeras pero no así a los segundos, por lo que parece evidente la necesidad de ampliación de esos programas con el propósito de alcanzar a estos niños, evitando así que se mantengan en una situación de vulnerabilidad e indefensión. Precisarán madres e hijos apoyo psicosocial para mantener el equilibrio 
emocional y la salud tanto física como psicológica. No se puede tolerar que produzcamos niños con poca salud psicológica por el solo hecho de ser hijo de su padre.

Una posible solución sería la de incorporar a estos niños como víctimas o afectados por la guerra, cuando se realiza esta categorización se les ignora, incluso en los escasos textos en los que se les menciona (como se ha puesto de relieve en las páginas precedentes), en ningún momento se les considera víctimas o afectados y si bien, como se ha referido supra, no encajan en la categoría de víctimas del conflicto, pues lo son de la sociedad o la comunidad en la que viven, afectados sí que lo son puesto que el origen de las discriminaciones de su entorno de las que son víctimas (en este supuesto sí resulta aplicable esta categoría) se encuentra precisamente en aquel conflicto.

Convengamos, en todo caso, que estos niños pueden dificultar la reconstrucción y la reconciliación tras el conflicto ${ }^{97}$, especialmente cuando se ha tratado de un conflicto armado interno, puesto que se pretende reconstruir una sociedad quebrada en la que esos niños son la prueba viviente del horror vivido. Pero en todo caso, por muchas dificultades que encontremos, mala será la sociedad que reconstruyamos si fundamentamos nuestras acciones en la ignorancia de estos niños. Por lo demás, si se trata de reconciliar, no podemos desdeñar la capacidad de estos menores «mestizos», para hacerlo, puesto que con ellos podemos tender puentes entre las partes en un conflicto sangriento para construir un futuro mejor para todos. No puede haber reconciliación ni reconstrucción si está basada sobre la discriminación y la injusticia.

Podemos realizar un paralelismo con las dificultades que presentan para la reconciliación y la reconstrucción entre los niños que nos ocupan y los niños soldados, que en algunos casos, como en el de Sierra Leona, han planteado alguna dificultad, en la medida en que han sido agresores en el conflicto en cuestión. A pesar de ello, lo cierto es que los programas de reconciliación y reconstrucción sí que se considera a los niños soldados dentro de estas estrategias, no así a los nacidos de los crímenes sexuales, lo que nos lleva a afirmar que a los últimos, que no participaron en la guerra, no los consideramos niños en cuanto a la necesidad de tenerlos en cuenta en la reconstrucción social y no lo hacemos no porque hayan causado mucho dolor, sino sencillamente porque su padre lo causó. Lo cierto es que no solo se les excluye de estos programas,

97 SETTo, D., «Children Born of Wartime Sexual...», op. cit., supra nota ${ }^{\circ} 10$. 
sino también del discurso internacional, no se encuentran en la discusión política tan siquiera, lo que les ubica en una ignorancia voluntaria que multiplica su vulnerabilidad.

Silencio que también ha mantenido la Asamblea General de Naciones Unidas en sus resoluciones que ha ignorado con carácter general a los niños. Tomemos como ejemplo el caso de Ruanda, en el que las resoluciones de la Asamblea General se refieren solo puntualmente a los niños de la guerra y no en todos los casos. Así, la Resolución 68/129, de 18 de diciembre de 2013, solicita que se incluya en el programa provisional de su $70^{\circ}$ periodo de sesiones un tema titulado «Asistencia a los supervivientes del genocidio cometido en 1994 en Rwanda, en particular a los huérfanos, las viudas y las víctimas de violencia sexual $\gg^{98}$, por lo que quedan fuera del alcance los hijos del enemigo salvo que se les contemple víctimas de violencia sexual, que lo serían en la medida en que son fruto de aquella y los huérfanos, que pueden serlo o no, pero huérfanos funcionales ${ }^{99}$.

No ha ocurrido lo mismo con la estrategia amplia de las Naciones Unidas sobre la asistencia y el apoyo a las víctimas de la explotación y los abusos sexuales cometidos por personal de las Naciones Unidas y personal asociado ${ }^{100}$, en la que la Asamblea General sí se refiere a estos niños para establecer la obligación de que reciban «de conformidad con sus necesidades personales, asistencia y apoyo para subsanar las consecuencias de índole médica, jurídica, psicológica y social derivadas directamente de esos actos, habida cuenta de lo que más conviene al niño». Es cierto que es la primera vez que se refiere a ellos para indicar la necesidad de adoptar las medidas necesarias para evitar que su origen produzca mayores daños en su derecho a la salud. Sin embargo, hemos de observar que el instrumento es una resolución y, en cuanto tal, con efectos meramente recomendatorios; y, exclusivamente respecto de una

98 En la Resolución 60/225, aprobada por la Asamblea General el 23 de diciembre de 2005, sobre la asistencia a los supervivientes del genocidio cometido en 1994 en Rwanda, en particular a los huérfanos, las viudas y las víctimas de violencia sexual, se pide «a la Mesa que considere la posibilidad de incluir en el programa del sexagésimo segundo periodo de sesiones de la Asamblea General un tema adicional titulado precisamente del mismo modo que la rúbrica que da título a esta resolución. Por su parte, en la resolución 62/96, aprobada por la Asamblea General el 1 de febrero de 2008, sobre la misma cuestión, se «Decide incluir 'en el programa provisional' de su sexagésimo cuarto periodo de sesiones la asistencia a los supervivientes del genocidio cometido en 1994 en Rwanda, en particular a los huérfanos, las viudas y las víctimas de violencia sexual».

99 La misma mención se encuentra en la resolución 59/137, de 10 de diciembre de 2004, resolución 66/228, de 23 de diciembre de 2011, 64/226, de 22 de diciembre de 2009.

100 Es la resolución 62/214, aprobada el 21 de diciembre de 2007. 
categoría de niños nacidos no como consecuencia de la violación atribuible al enemigo, sino al que venía precisamente a proteger a la población: el personal de Naciones Unidas y el personal asociado, por lo que no resulta aplicable a los niños que nos ocupan.

En todo caso, si no se consigue integrar socialmente a los niños nacidos de los crímenes sexuales, el Estado estará incumpliendo sus obligaciones internacionales en materia de derechos humanos, que en lo que se refieren a los niños se fundamentan claramente en el principio del interés superior del menor, y menores titulares de todos los derechos humanos son también los nacidos de crímenes sexuales. Uno de los derechos fundamentales de todas las personas es el derecho a la vida y es evidente que con el infanticidio se vulnera. No existen dudas al respecto. Los Estados no deben forzar a las mujeres o a sus familias a adoptar estas soluciones, que son las únicas que se les ofrece en situaciones como las que han de pasar siendo víctimas de violaciones, en muchos casos reiteradas, no desean hacerse cargo de las consecuencias de tan atroces crímenes. En este punto, la legalización del aborto y su práctica barata y con seguridad evitaría sin duda estos infanticidios. También el establecimiento y la información acerca de la entrega en adopción de los niños nacidos con garantías de anonimato beneficiaría la situación de estos pequeños, porque no se trata de victimizar más a las mujeres, sino de idear mecanismos eficaces precisamente para evitarlo.

Resulta cuando menos curioso que, por ejemplo, en la página de la Oficina del representante especial del Secretario General para los niños y los conflictos armados, en el apartado relativo a los efectos del conflicto se menciona a los niños desplazados internos, niños detenidos o la niña, pero en ningún momento hay mención a los nacidos como consecuencia de los crímenes sexuales. Sí se trata como una de las violaciones más graves la violencia sexual, refiriéndose a los posibles embarazos e indicando los problemas que de ello deriva para la madre, pero no se trabaja en clave de los niños de la guerra ${ }^{101}$. El argumento para la exclusión puede ser que se parte del niño afectado por la guerra y no con origen en ella ${ }^{102}$, en todo caso, estos últimos también son afectados por la contienda, aunque no del mismo modo que los demás. Solo

${ }^{101}$ La página general es: https://childrenandarmedconflict.un.org/es/, la relativa a la violencia sexual: https://childrenandarmedconflict.un.org/es/efectos-del-conflicto/infracciones-mas-graves/violencia-sexual/

102 Ver en este sentido el Informe de Graça Machel, sobre el impacto de la guerra en los conflictos armados, de 1996, en https://www.unicef.org/graca/ 
evidenciando esta realidad podremos lograr un grado de protección razonable para su situación.

Respecto de los niños nacidos de crímenes sexuales, el registro del nacimiento le confiere la identidad, la nacionalidad y la existencia jurídica. Es preciso por tanto fomentar la obligación de registrar a los nacidos para evitar vulneraciones de otros derechos. Todos tenemos derecho al registro de nuestra identidad, sin este paso previo no existimos jurídicamente y se nos negará no solo la nacionalidad, sino también la educación, la sanidad y cualquier otro beneficio social.

Como en tantas otras cuestiones relacionadas especialmente con los derechos humanos, se advierte en ésta la insuficiencia del derecho para resolver problemas. Es cierto que es un elemento importante, pero sin protección, preparación y pedagogía las categorías jurídicas no funcionan porque pueden considerarse imposiciones exógenas para los grupos humanos por lo que sus integrantes tienden a rebelarse contra ellas. La educación es un importante instrumento para cambiar las percepciones.

La insuficiencia del derecho se muestra incluso con las normas de derecho interno, hay textos constitucionales, como la constitución Ruandesa que proclaman principios y derechos que no se han respetado respecto de los niños que nos ocupan, como el principio de igualdad de todos los ciudadanos ${ }^{103}$, la relevancia de la familia como fundamento de la sociedad nacional ${ }^{104}$, la obligación de cuidado de los niños y la legislación estatal protectora de la familia, del niño y de la madre, así como la titularidad de los menores de edad del derecho a medidas de protección específicas ${ }^{105}$. Siguiendo con el mismo Estado, su Ley 2/98, de enero de 1998 crea un fondo de asistencia a supervivientes de genocidio $^{106}$. Este texto legal excluye a los niños nacidos como consecuencia

${ }^{103} \mathrm{El}$ artículo 16 afirma: «Tous les êtres humains sont égaux devant la loi. Ils ont droit, sans aucune distinction, à une égale protection par la loi», ver el texto en http://www.wipo.int/wipolex/es/ text.jsp?file_id=194316

${ }^{104} \mathrm{El}$ artículo 27 contiene la siguiente redacción: «La famille, base naturelle de la société rwandaise, est protégée par l'Etat. Les deux parents ont le droit et le devoir d'éduquer leurs enfants. L'Etat met en place une législation et des institutions appropriées pour la protection de la famille, de l'enfant et de la mère en particulier, en vue de son épanouissement».

${ }^{105} \mathrm{El}$ artículo 28: «Tout enfant a droit, de la part de sa famille, de la société et de l'Etat, aux mesures spéciales de protection qu'exige sa condition, conformément aux droits national et international».

${ }^{106} \mathrm{El}$ texto de la ley en francés puede verse en http://www.refworld.org/cgi-bin/texis/vtx/rwmain/ opendocpdf.pdf? reldoc $=y \&$ docid $=52 \mathrm{df} 999 \mathrm{e} 4$ 
de violaciones o maternidad forzada, porque solo ampara a los supervivientes del genocidio y estos no lo son en el sentido que lo establece esta Ley.

Por tanto, si ni el Derecho interno ni el Derecho internacional se preocupan por estos niños, difícilmente construiremos un mundo mejor, porque la exclusión de los vulnerables solo genera injusticia y marginación social y, convengamos, que no son contextos de los que podamos sentirnos orgullosos además de inadaptación y sufrimiento por parte de quienes se ven así ignorados y maltratados. 